\title{
Effects of Inhibiting Antioxidant Pathways on Cellular Hydrogen Sulfide and
}

\section{Polysulfide Metabolism}

Kenneth R. Olson ${ }^{\mathrm{a}, \mathrm{b}}$ and Yan Gao ${ }^{\mathrm{a}}$

a. Indiana University School of Medicine - South Bend Center, South Bend, Indiana 46617 USA

b. Department of Biological Sciences, University of Notre Dame, Notre Dame IN 46556

\section{Running Head: Antioxidant Inhibitors and RSS Metabolism}

\section{Address correspondence to:}

Kenneth R. Olson, Ph.D.

Indiana University School of Medicine -South Bend

Raclin Carmichael Hall

1234 Notre Dame Avenue

South Bend, IN 46617

Phone: (574) 631-7560

Fax: (574) 631-7821

e-mail: olson.1@nd.edu

This is the author's manuscript of the article published in final edited form as: 


\section{ABSTRACT}

Elaborate antioxidant pathways have evolved to minimize the threat of excessive reactive oxygen species (ROS) and to regulate ROS as signaling entities. ROS are chemically and functionally similar to reactive sulfide species (RSS) and both ROS and RSS have been shown to be metabolized by the antioxidant enzymes, superoxide dismutase and catalase. Here we use fluorophores to examine the effects of a variety of inhibitors of antioxidant pathways on metabolism of two important RSS, hydrogen sulfide $\left(\mathrm{H}_{2} \mathrm{~S}\right.$ with AzMC) and polysulfides $\left(\mathrm{H}_{2} \mathrm{~S}_{\mathrm{n}}\right.$, where $n=2-7$, with SSP4) in HEK293 cells. Cells were exposed to inhibitors for up to 5 days in normoxia $\left(21 \% \mathrm{O}_{2}\right)$ and hypoxia $\left(5 \% \mathrm{O}_{2}\right)$, conditions also known to affect ROS production. Decreasing intracellular glutathione (GSH) with L-buthionine-sulfoximine (BSO) or diethyl maleate (DEM) decreased $\mathrm{H}_{2} \mathrm{~S}$ production for 5 days but did not affect $\mathrm{H}_{2} \mathrm{~S}_{\mathrm{n}}$. The glutathione reductase inhibitor, auranofin, initially decreased $\mathrm{H}_{2} \mathrm{~S}$ and $\mathrm{H}_{2} \mathrm{~S}_{\mathrm{n}}$ but after two days $\mathrm{H}_{2} \mathrm{~S}_{n}$ increased over controls. Inhibition of peroxiredoxins with conoidin A decreased $\mathrm{H}_{2} \mathrm{~S}$ and increased $\mathrm{H}_{2} \mathrm{~S}_{\mathrm{n}}$, whereas the glutathione peroxidase inhibitor, tiopronin, increased $\mathrm{H}_{2} \mathrm{~S}$. Aminoadipic acid, an inhibitor of cystine uptake did not affect either $\mathrm{H}_{2} \mathrm{~S}$ or $\mathrm{H}_{2} \mathrm{~S}_{\mathrm{n}}$. In buffer, the glutathione reductase and thioredoxin reductase inhibitor, 2-AAPA, the glutathione peroxidase mimetic, ebselen, and tiopronin variously reacted directly with AzMC and SSP4, reacted with $\mathrm{H}_{2} \mathrm{~S}$ and $\mathrm{H}_{2} \mathrm{~S}_{2}$, or optically interfered with AzMC or SSP4 fluorescence. Collectively these results show that antioxidant inhibitors, generally known for their ability to increase cellular ROS, have various effects on cellular RSS. These findings suggest that the inhibitors may affect cellular sulfur metabolism pathways that are not related to ROS production and in some instances they may directly affect RSS or the methods used to measure them. They also 
24 illustrate the importance of carefully evaluating RSS metabolism when biologically or

25 pharmacologically attempting to manipulate ROS.

26

27 Key Words: reactive sulfide species; reactive oxygen species; antioxidants 


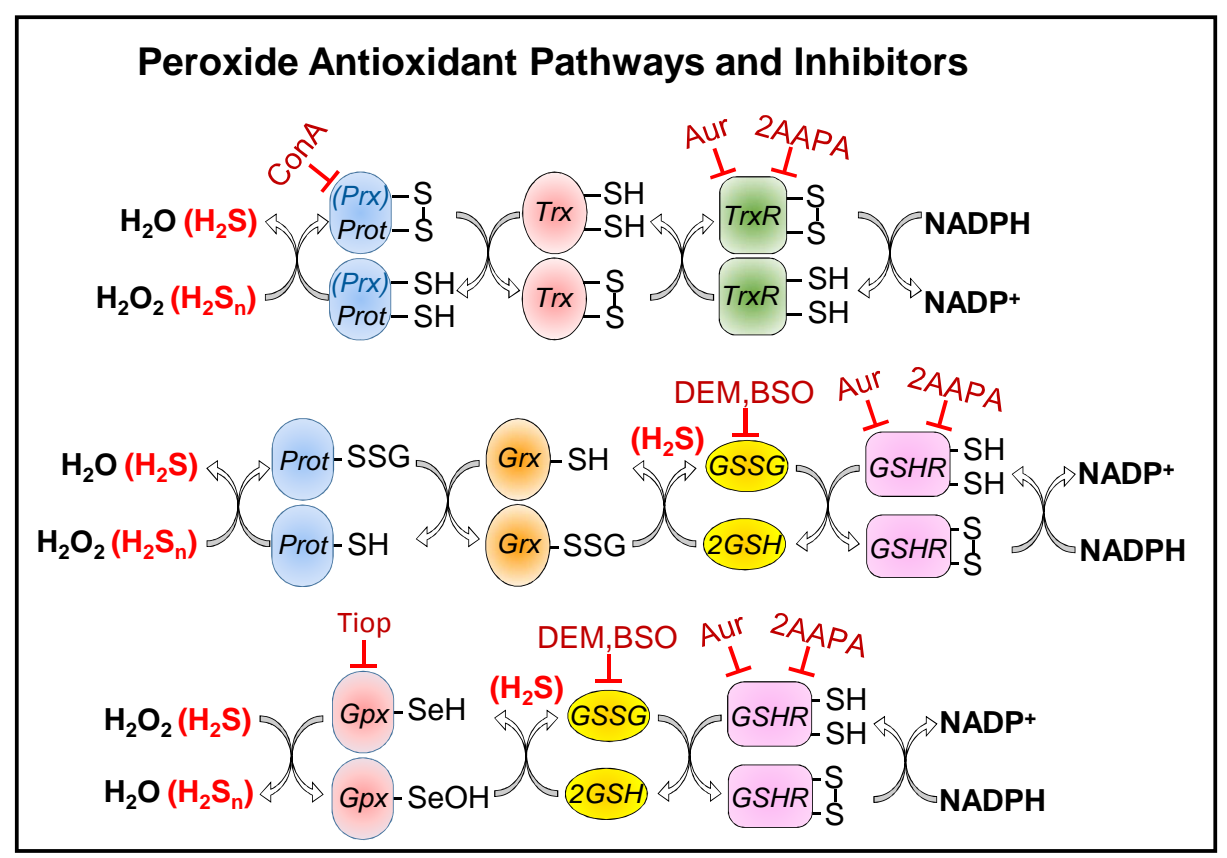




\section{Introduction}

It is becoming more apparent that redox environments in various intracellular compartments are physiologically regulated to optimize electron transfer and prevent electrons from 'wandering off' and disrupting cellular processes. Although, numerous oxidants can arise from a variety of intracellular processes, or be ingested in the diet, the production of reactive oxygen species (ROS), namely peroxide $\left(\mathrm{H}_{2} \mathrm{O}_{2}\right)$ has received the most attention as it has been implicated a variety of aspects of oxidative stresses from signaling (eustress) to mobilization of antioxidant responses (oxidative stress), and if this fails the resulting oxidative distress can lead to catastrophic consequences [1-19].

Regulation of, and protection from ROS is attributed to a hierarchy of antioxidant mechanisms that include ROS buffers and a compliment of enzymes that facilitate transfer of electrons from NADPH to the oxidant or oxidized cellular constituent, the latter often a thiol on a regulatory or structural protein. Thiols are also the redox currency of the major intracellular redox buffer, glutathione, and the cadre of redox enzymes, peroxiredoxins, thioredoxins, thioredoxin reductases, glutaredoxins and glutathione reductases employed to maintain this balance. Chemically targeting these antioxidant systems has been used to examine their relative regulatory roles as well as to disrupt redox balance as a therapeutic tool [20-31]. We have noted striking similarities between ROS and reactive sulfide species (RSS) and have proposed that in some instances the former could be mistaken for the latter in cellular functions [32]. Sequential one-electron reductions of $\mathrm{O}_{2}$ produces superoxide $\left(\mathrm{O}_{2}{ }^{-}\right)$, hydrogen peroxide $\left(\mathrm{H}_{2} \mathrm{O}_{2}\right)$, hydroxyl radical $\left(\mathrm{HO}^{\circ}\right)$ and $\mathrm{H}_{2} \mathrm{O}$, whereas one-electron oxidation of hydrogen sulfide $\left(\mathrm{H}_{2} \mathrm{~S}\right)$ progressively forms a thiyl radical (HS $)$, hydrogen persulfide $\left(\mathrm{H}_{2} \mathrm{~S}_{2}\right)$ and persulfide "supersulfide" radical $\left(\mathrm{HS}_{2}{ }^{\circ}\right)$ before terminating in elemental sulfur $\left(\mathrm{S}_{2}\right)$, the latter usually 
cyclizing to $S_{8}$. The primary target of both peroxide and persulfide is the above-mentioned cysteine on regulatory proteins and the effects of peroxidation or persulfidation on the function of a number of proteins has been shown to be identical [17,33-40]. Furthermore, many methods routinely employed to measure ROS also detect RSS, at times with greater sensitivity [41].

Although the "Redox Code" posits that concept of antioxidant protection was believed to be "richly elaborated in an oxygen-dependent life, where activation/deactivation cycles involving $\mathrm{O}_{2}$ and $\mathrm{H}_{2} \mathrm{O}_{2}$ contribute to spatiotemporal organization for differentiation, development, and adaptation to the environment" [42], an argument can be made for antioxidants in the regulation of RSS. Essentially all antioxidant buffers and above-mentioned enzymes appeared within the first several hundred million years after life's beginnings 3.8 billion years ago [43-51]. At this time the oceans were anoxic and sulfidic $[52,53]$ and it would take over a billion years for the "great oxidation event" to slightly nudge atmospheric $\mathrm{O}_{2}$. It wasn't until 600 million years ago, after nearly seven-eighths of evolution had passed, before the oceans became oxic. As the origins of antioxidant mechanisms likely coincided with the advent of anoxygenic photosynthesis, a process that has been proposed to oxidize $\mathrm{H}_{2} \mathrm{~S}$ to polysulfides and reduce $\mathrm{CO}_{2}$ to methane and other organic compounds [32] it would seem that control of sulfur-based redox reactions would have been a priority, perhaps not only for redox balance but for general metabolism. We proposed that many of these pathways remain in extant animals and perform similar functions.

We recently examined the possibility that sulfur was metabolized by two antioxidant enzymes, superoxide dismutase (SOD) and catalase, and indeed this appeared to be the case. Both $\mathrm{Cu} / \mathrm{Zn}$ and $\mathrm{Mn}$ SOD oxygen-dependently oxidized $\mathrm{H}_{2} \mathrm{~S}$ to polysulfides, initially forming persulfide $\left(\mathrm{H}_{2} \mathrm{~S}_{2}\right)$ and subsequently longer chain polysulfides $\left(\mathrm{H}_{2} \mathrm{~S}_{\mathrm{n}}\right.$ where $\left.\mathrm{n}=3-5\right)$ but did not 
metabolize polysulfides [54]. Bovine catalase also oxidized $\mathrm{H}_{2} \mathrm{~S}$ to polysulfides in the presence of either $\mathrm{O}_{2}$ or $\mathrm{H}_{2} \mathrm{O}_{2}$, whereas in hypoxia it produced $\mathrm{H}_{2} \mathrm{~S}$ from either thioredoxin or the sulfurreductant dithiothreitol (DTT), a process that required NADPH [55]. Furthermore, the partial pressure of oxygen at which the catalase switched from an oxidase to a reductase $\left(\mathrm{P}_{50}\right)$ which is $20 \mathrm{mmHg}$, is striking similar to the $\mathrm{P}_{50}$ of the oxyhemoglobin saturation curve ( $26 \mathrm{mmHg}$ ) suggesting that catalase, which is abundant in red blood cells, oxidizes $\mathrm{H}_{2} \mathrm{~S}$ during normoxia, whereas as blood $\mathrm{Po}_{2}$ falls, not only is $\mathrm{O}_{2}$ unloaded from hemoglobin, but vasodilator $\mathrm{H}_{2} \mathrm{~S}$ is produced to augment $\mathrm{O}_{2}$ delivery.

In the present study we further examine sulfur (RSS) metabolism in HEK293 cells by blocking endogenous antioxidant pathways while monitoring endogenous $\mathrm{H}_{2} \mathrm{~S}$ and polysulfides with specific fluorophores (AzMC and SSP4, respectively). We show that these antioxidant inhibitors have profound effects on cellular RSS that are not consistent with concomitant effects on ROS and propose that some of the effects of manipulating cellular antioxidant pathways may be mediated by RSS.

\section{Materials and methods}

\subsection{Chemicals}

SSP4 (3', 6'-Di(O-thiosalicyl)fluorescein) was purchased from Dojindo molecular Technologies Inc. (Rockville, MD). All other chemicals were purchased either from SigmaAldrich (St. Louis, MO) or ThermoFisher Scientific (Grand Island, NY). Please note that we use $\mathrm{H}_{2} \mathrm{~S}$ to denote the total sulfide added (sum of $\mathrm{H}_{2} \mathrm{~S}+\mathrm{HS}^{-}$) usually derived from $\mathrm{Na}_{2} \mathrm{~S}$. Also, 

physiological conditions [56]. Phosphate buffer (PBS; in mM): $137 \mathrm{NaCl}, 2.7, \mathrm{KCl}, 8 \mathrm{Na}_{2} \mathrm{HPO}_{4}$, $2 \mathrm{NaH}_{2} \mathrm{PO}_{4}$. $\mathrm{pH}$ was adjusted with $10 \mathrm{mM} \mathrm{HCl}$ or $\mathrm{NaOH}$ to 7.4 .

\subsection{Effects of inhibitors on sulfur metabolism in cells}

Human embryonic kidney (HEK293) cells were cultured and maintained at $37^{\circ} \mathrm{C}$ in a $5 \%$ $\mathrm{CO}_{2}$ humidified incubator with $21 \% \mathrm{O}_{2}$ supplemented with DMEM (low glucose) containing $10 \%$ FBS and $1 \%$ Pen/Strep. In a typical experiment they were transferred from a T-25 tissue culture flask to two 96 well plates with gas-permeable bottoms (Coy Laboratory Products, Inc. grass Lake, MI) and grown to $80-95 \%$ confluency. The cells were then treated with either an $\mathrm{H}_{2} \mathrm{~S}$ sensitive fluorophore 7-azido-3-methylcoumarin (AzMC, $25 \mu \mathrm{M}$ ) or a polysulfide sensitive

7
fluorophore 3',6'-Di(O-thiosalicyl)fluorescein (SSP4, $10 \mu \mathrm{M})$. Excitation/emission wavelengths for AzMC and SSP4 were 365/450 and 482/515, respectively per manufacture's recommendations. Fluorescence was measured on a SpectraMax M5e plate reader (Molecular Devices, Sunnyvale, CA) according to the manufacturer's recommendations Inhibitors of $\mathrm{H}_{2} \mathrm{~S}$ biosynthesis or sulfur doors were typically added after an initial baseline reading and one plate was returned to the $21 \% \mathrm{O}_{2}$ incubator (normoxia) and the other placed in a model $856-\mathrm{HYPO}$ hypoxia chamber (Plas Labs, Inc. Lansing, MI) and incubated in 5\% $\mathrm{O}_{2} / 5 \% \mathrm{CO}_{2}$ balance $\mathrm{N}_{2}$ (hypoxia) at $37^{\circ} \mathrm{C}$ for 3-5 days. Previous studies have shown that this prolonged hypoxia produces a sustained increase in cellular $\mathrm{H}_{2} \mathrm{~S}$ and these studies were designed to determine if any inhibitors specifically affected the hypoxic response.

$(7$

\subsection{Effects of inhibitors on fluorescence and sulfur metabolism in buffer}


The inhibitors used in this study could give an erroneous impression of an effect on

120 cellular sulfur metabolism if they directly interacted with AzMc and SSP4 or $\mathrm{H}_{2} \mathrm{~S}$ and

121 polysulfides. Three groups of experiments were performed to examine these possibilities. In the

122 first group, the inhibitors were added directly to the fluorophores to determine if they specifically

123 activated the fluorophores. In the second group, the inhibitors were added to concomitantly with

$124200 \mu \mathrm{M} \mathrm{H}_{2} \mathrm{~S}$ and either AzMC or SSP4. A decrease in AzMC fluorescence would suggest that

125 either the inhibitors catalyzed $\mathrm{H}_{2} \mathrm{~S}$ consumption or there was a direct interference of the reaction

126 between $\mathrm{H}_{2} \mathrm{~S}$ and AzMC. An increase in SSP4 fluorescence in these experiments would suggest

127 that the inhibitors catalyzed the oxidation of $\mathrm{H}_{2} \mathrm{~S}$ to polysulfides. In the third group of

128 experiments $10 \mu \mathrm{M}$ of $\mathrm{H}_{2} \mathrm{~S}$ was incubated with AzMC, or $30 \mu \mathrm{M}$ of $\mathrm{K}_{2} \mathrm{~S}_{\mathrm{n}}$ was incubated with

129 SSP4 for 120 min to determine if the inhibitors interfered with fluorescence of AzMC or SSP4

130 after thethe fluorophores were activated by the sulfur moiety. In these experiments the $\mathrm{H}_{2} \mathrm{~S}$ and

$131 \quad \mathrm{~K}_{2} \mathrm{~S}_{\mathrm{n}}$ concentrations were chosen to produce approximately the same fluoresence as that

132 observed in the cell experiments and $120 \mathrm{~min}$ allowed for the fluorophore-sulfur reaction to be

133 completed.

134 The compounds of interest were aliquoted into black 96 well plates in a darkened room

135 and fluorescence was measured on a SpectraMax M5e plate reader (Molecular Devices,

136 Sunnyvale, CA). Fluorescence was typically measured every 10 min over $90 \mathrm{~min}$. The inhibitor

137 concentrations were selected to bracket the concentrations used in the cell experiments. All

138 experiments were performed at room temperature $\left(20^{\circ} \mathrm{C}\right)$.

139

140

2.4. Cell viability 
Cell viability was determined using the PrestoBlue fluorophore per manufacturer's directions. PrestoBlue was either added at the end of an experiment or to PBS and fluorescence measured 1 and $2 \mathrm{~h}$ later at 535/615 $\mathrm{nm}(\mathrm{Ex} / \mathrm{Em})$.

\subsection{Verification of AzMC specificity}

An anonymous reviewer expressed some concern regarding the specificity of AzMC as a $\mathrm{H}_{2} \mathrm{~S}$ fluorophore. To examine this we first examined the effects of GSH, $-3 \mathrm{MP}, \mathrm{H}_{2} \mathrm{O}_{2}$ and the 148 NO donor sodium nitroprusside on AzMC fluorescence in PBS. We then incubated HEK293 149 cells with inhibitors of $\mathrm{H}_{2} \mathrm{~S}$ biosynthesis, propargylglycine (PPG; $10 \mathrm{mM}$ ) and $1 \mathrm{mM}$ aminooxyacetate (AOA; $1 \mathrm{mM})$. PPG is a relatively selective inhibitor of cystathionine $\gamma$ lyase and AOA is an inhibitor of both CSE and cystathionine $\beta$-synthase (CBS).

\section{Results}

\subsection{Calculations}

Results are expressed as mean + SE. Statistical analysis was determined by one-way ANOVA with Holm-Sidak for multiple comparisons. Significance was assumed at $p \leq 0.05$.

\subsection{Effects of BSO and DEM on intracellular $\mathrm{H}_{2} \mathrm{~S}$ and polysulfides in HEK293 cells}

Both L-buthionine-sulfoximine (BSO) and diethyl maleate (DEM) decreased intracellular GSH and increased ROS in primary cortical cultures containing both neurons and astrocytes [57]. The concentration-dependent effects of BSO and DEM on $\mathrm{H}_{2} \mathrm{~S}$ (AzMC fluorescence) in both normoxic $\left(21 \% \mathrm{O}_{2}\right)$ and hypoxic $\left(5 \% \mathrm{O}_{2}\right)$ HEK293 cells are shown in Fig. 1. Although the 
decrease in AzMC fluorescence between $0.3 \mu \mathrm{M}$ BSO and $1 \mu \mathrm{M}$ BSO supporting the conclusion that both BSO and DEM concentration-dependently decreased AzMC fluorescence in normoxic

\subsection{Effects of cystine, BSO and DEM on $\mathrm{H}_{2} \mathrm{~S}$ and polysulfide metabolism in HEK293 cells}

Although both BSO and DEM decrease intracellular GSH and increase ROS, DEM increases cystine uptake while BSO decreases it [57]. In order to determine if cystine affected the actions of these inhibitors on cellular sulfur metabolism we incubated HEK293 cells with combinations of $200 \mu \mathrm{M}$ cystine, $10 \mu \mathrm{M}$ BSO and $100 \mu \mathrm{M}$ DEM (Fig. 2). Cystine decreased intracellular $\mathrm{H}_{2} \mathrm{~S}$, but it was less than half as effective as either BSO or DEM and the effects of either BSO or DEM were not affected by addition of cystine. SSP4 fluorescence was unaffected 
results suggest that the effects of BSO and DEM on intracellular $\mathrm{H}_{2} \mathrm{~S}$ metabolism are independent of cystine uptake and not related to their effects on intracellular ROS.

Figure 2 also shows that cystine alone decreases AzMC but does not affect SSP4 fluorescence in HEK293 cells. Cystine also had direct effects on the fluorophores in buffer but these were opposite of those produced in cells (Fig. S3). Cystine slightly increased fluorescence of both AzMC and SSP4 alone and it concentration-dependently increased SSP4 fluorescence when added in conjunction with $\mathrm{H}_{2} \mathrm{~S}$. Cystine produced approximately a $20 \%$ increase in AzMC fluorescence when added $120 \mathrm{~min}$ after AzMC but this was not dependent on cysteine concentration; cystine did not affect fluorescence of SSP4 pre-incubated with $\mathrm{K}_{2} \mathrm{~S}_{\mathrm{n}}$ (Fig. S4).

\subsection{Effects of auranofin on intracellular $\mathrm{H}_{2} \mathrm{~S}$ and polysulfides in HEK293 cells}

The effects of cystine on cellular polysulfides remain to be clarified.

Auranofin is an irreversible inhibitor of glutathione reductase (GSHR) and increases intracellular ROS [27,28,58,59]. The concentration-dependent effects of auranofin on sulfur metabolism are shown in Fig. 3. Auranofin concentration-dependently decreased the time dependent rate of both AzMC and SSP4 fluorescence increase in normoxic and hypoxic cells. The effects of auranofin in buffer are shown in Fig. S5. In buffer, auranofin did not directly react with otherwise unactivated fluorophore nor did it affect the reaction of AzMC with $\mathrm{H}_{2} \mathrm{~S}$. However, auranofin decreased SSP4 fluorescence in the presence of $\mathrm{H}_{2} \mathrm{~S}$ but not in the presence of $\mathrm{H}_{2} \mathrm{~S}$-activated AzMC or $\mathrm{K}_{2} \mathrm{~S}_{\mathrm{n}}$-activated SSP4. The concentration-dependent decrease in SSP4 fluorescence produced by auranofin in HEK293 cells was evident at the initial 

between the un-treated and auranofin-treated samples suggesting that the anurafin effects were 209 indirect.

\subsection{Effects of combined auranofin and BSO or DEM treatment on $\mathrm{H}_{2} \mathrm{~S}$ and polysulfide}

212 metabolism in HEK293 cells

The combined effects of $10 \mu \mathrm{M}$ BSO, $100 \mu \mathrm{M}$ DEM and either 3 or $10 \mu \mathrm{M}$ auranofin are shown in Fig. 4. In these experiments the inhibitors were added to the cells on the first day,

215 whereas the fluorophores were added to different groups of cells on day $1,2,3$ and 4 . This 216 combination of inhibitors nearly completely inhibited $\mathrm{H}_{2} \mathrm{~S}$ production when applied on the first 217 day and this level of inhibition remained for the duration of the experiment. Polysulfide production was not appreciably affected with $3 \mu \mathrm{M}$ auranofin when the SSP4 was given on the first day but was decreased with $10 \mu \mathrm{M}$ auranofin. However, the degree of inhibition of SSP4 fluorescence appeared to progressively wane when the SSP4 was given after day one and by days 2-3 SSP4 fluorescence was greater in auranofin-treated cells. These effects on AzMC fluorescence are consistent with the individual effects of the inhibitors whereas there appears to

\subsection{Effects of conoidin A on $\mathrm{H}_{2} \mathrm{~S}$ and polysulfide metabolism in HEK293 cells}

Conoidin A covalently binds and inhibits peroxiredoxins [60]. The effects of conoidin A on sulfur metabolism in HEK293 cells are shown in Fig. 5. Conoidin A concentration- 
normoxic and hypoxic HEK293 cells. With $100 \mu \mathrm{M}$ conoidin A AzMC fluorescence was severely depressed, even at $\mathrm{t}=0 \mathrm{~h}$ suggesting that conoidin A directly interfered with AzMC, and indeed this appeared to be the case. In buffer conoidin A concentration-dependently decreased AzMC fluorescence by itself, in conjunction with $\mathrm{H}_{2} \mathrm{~S}$, and after $\mathrm{H}_{2} \mathrm{~S}$ had reacted with AzMC for $120 \mathrm{~min}$ (Fig. S6). In all instances there was an apparent threshold of $3 \mu \mathrm{M}$ (5\% inhibition) and at $100 \mu \mathrm{M}$ more than half of the AzMC fluorescence was inhibited. These results suggest that with conoidin A concentrations above $3 \mu \mathrm{M}$ the effects on cellular AzMC fluorescence are indirect and probably due to optical quenching. However, the inhibitory effects of $1 \mu \mathrm{M}$ conoidin A on AzMC fluorescence in cells could be due to direct inhibition of cellular $\mathrm{H}_{2} \mathrm{~S}$ as this concentration did not affect AzMC fluorescence in buffer. Conoidin A also decreased SSP4

\subsection{Effects of tiopronin on $\mathrm{H}_{2} \mathrm{~S}$ and polysulfide metabolism in HEK293 cells}

fluorescence in buffer (Fig. S6), clearly the opposite of its effects in cells, indicating that conoidin A directly increases intracellular polysulfides.

The effects of tiopronin, an inhibitor of cystine uptake, on AzMC and SSP4 fluorescence in HEK293are shown in Fig. 6. Tiopronin concentration-dependently increased AzMC fluorescence in normoxic HEK293 cells and this was further increased in hypoxic cells. For example, at $21 \mathrm{~h} 1 \mathrm{mM}$ tiopronin increased AzMC fluorescence 4.9-fold in hypoxic cells compared to a 3.4-fold increase in normoxic cells. After $21 \mathrm{~h}$ AzMC fluorescence progressively declined in hypoxic cells but continued to rise, albeit slowly in normoxic cells. In buffer tiopronin increased AzMC fluorescence by approximately 40\% (Fig. S7) but this was only 1500 to 2000 fluorescence units compared to the increase of over 10,000 fluorescence observed in cells. When added in conjunction with $\mathrm{H}_{2} \mathrm{~S}$, tiopronin decreased AzMC fluorescence (Fig. S7) 
by $40 \%$, but when added 120 min after AzMC and $\mathrm{H}_{2} \mathrm{~S}$ tiopronin did not inhibit fluorescence between $500 \mu \mathrm{M}$ and $2 \mathrm{mM}$ and inhibited it by only $25 \%$ at $4 \mathrm{mM}$. These results indicate that topronin substantially increases intracellular $\mathrm{H}_{2} \mathrm{~S}$ and that this increase is even greater in hypoxic cells.

SSP4 fluorescence was decreased by tiopronin in normoxia and hypoxia with the most notable response in hypoxic cells treated with $1 \mathrm{mM}$ tiopronin. As shown in Fig. S7, tiopronin that tiopronin likely has little effect on intracellular polysulfides.

\subsection{Effects of ebselen on $\mathrm{H}_{2} \mathrm{~S}$ and polysulfide metabolism in HEK293 cells}

Effects of the glutathione peroxidase and peroxiredoxin mimetic on AzMC and SSP4 AzMC fluorescence in normoxic and hypoxic HEK293 cells but had minimal effects on SSP4 fluorescence with the exception of a delayed increase in fluorescence. The effects of ebselen on AzMC fluoresence in cells are likely indirect. As shown in Fig. S8, while ebselen did not directly react with buffer, it decreased AzMC fluorescence by $70 \%$ when added concurrently with $\mathrm{H}_{2} \mathrm{~S}$ but only slightly ( $<20 \%$ ) decreased fluorescence when added 120 min after $\mathrm{H}_{2} \mathrm{~S}$. Ebselen also profoundly increased SSP4 fluorescence (600\%) when added concurrently with $\mathrm{H}_{2} \mathrm{~S}$ and SSP4 but did not affect SSP4 fluorescence when added directly to SSP4 or 120 min after $\mathrm{K}_{2} \mathrm{~S}_{\mathrm{n}}$ was added to SSP4. These results suggest that ebselen directly catalyzes polysulfide formation from $\mathrm{H}_{2} \mathrm{~S}$. Additional studies are required to clarify ebselen's effects in cells. 


\subsection{Effects of 2-AAPA on $\mathrm{H}_{2} \mathrm{~S}$ and polysulfide metabolism in HEK293 cells}

The irreversible inhibitor of glutathione reductase (GSHR) and thioredoxin reductase (TrxR), 2-AAPA, concentration-dependently decreased AzMC fluorescence in normoxic and hypoxic HEK293 cells (Fig. 8). 2-AAPA also increased cellular SSP4 fluorescence, which at 20 $\mu \mathrm{M}$ was 3-4 times that of untreated cells. This increase was noted immediately after application of 2-AAPA and it declined by $\sim 15 \%$ within the first $4 \mathrm{~h}$.

In buffer, 2-AAPA appeared to directly react with AzMC, increasing fluorescence by approximately $40 \%$ at all concentrations (10, 20 and $40 \mu \mathrm{M}$; Fig. S9). But when 2-AAPA was added to AzMC in the presence of $100 \mu \mathrm{M} \mathrm{H}_{2} \mathrm{~S}$ it appeared to slightly decrease fluorescence but this was due to variability in the initial concentrations of fluorophore ( $\mathrm{t}=0 \mathrm{~min})$ and not to 2AAPA; the ratio of fluorescence between $\mathrm{H}_{2} \mathrm{~S}$ and 10,20 or $40 \mu \mathrm{M} 2$-AAPA at $\mathrm{t}=0 \mathrm{~min}(0.74$, 1.10 and 0.65 , respectively) was not appreciably different from their ratios at $10 \min (0.75,0.99$, $0.65)$ or $90 \min (0.86,0.97,0.70)$. A minimal $(<10 \%)$ decrease in fluorescence was also observed when 2-AAPA was added 120 min after $\mathrm{H}_{2} \mathrm{~S}$ had reacted with AzMC. Collectively, these results suggest that 2-AAPA may directly decrease intracellular $\mathrm{H}_{2} \mathrm{~S}$, however this needs to be confirmed.

The effects of 2-AAPA on intracellular SSP4 fluorescence, appears to be due to direct interactions between 2-AAPA and SSP4 (Fig. S9). Direct addition of 2-AAPA to SSP4 produced a concentration- and time-dependent increase in fluorescence that for 10, 20 and $40 \mu \mathrm{M}$ 2-AAPA was 37, 55 and 77 times greater, respectively than SSP4 alone at $90 \mathrm{~min}$. 2-AAPA also increased fluorescence when SSP4 was added to $\mathrm{H}_{2} \mathrm{~S}$, albeit to a lesser degree. However, 2AAPA did not affect fluorescence of SSP4 after the latter had reacted with polysulfides, presumably because at this time there was little un-reacted SSP4 left. Although these results do 
not provide any direct information on intracellular polysulfide metabolism, they clearly illustrate the need to carefully evaluate potential interfering reactions with test compounds and fluorophores.

\subsection{Effects of aminoadipic acid on $\mathrm{H}_{2} \mathrm{~S}$ and polysulfide metabolism in HEK293 cells}

Aminoadipic acid is a competitive substrate for the system $\mathrm{X}_{\mathrm{c}}^{-}$transporter and decreases

\subsection{Short-term effects of select inhibitors}

A number of the inhibitors used in this study had apparent effects on $\mathrm{H}_{2} \mathrm{~S}$ and polysulfide metabolism within the first 4 hours. These effects were then examined on a shorter time scale to get a better appreciation of their impact on $\mathrm{H}_{2} \mathrm{~S}$ and polysulfide metabolism.

As shown in Fig. 10, BSO did not appreciably affect AzMC fluorescence, whereas an inhibitory effect of $300 \mu \mathrm{M}$ DEM was evident within the first hour. This is as expected because BSO inhibits GSH synthesis but does not immediately react with GSH, whereas DEM directly reacts with GSH. By the first hr, $1 \mathrm{mM}$ tiopronin increased $\mathrm{H}_{2} \mathrm{~S}$. The effects of $300 \mu \mathrm{M}$ and 100 $\mu \mathrm{M}$ tiopronin became evident by hrs 2 and 3 , respectively. The inhibitory effects of conoidin A on AzMC fluorescence were evident even at the initial ( $\mathrm{t}=0 \mathrm{hr}$ ) sample suggesting that these 
were due to a direct inhibitory effect on the fluorphore which is supported by the buffer studies (Fig. S6).

Conoidin A produced concentration-dependent increases in SSP4 fluorescence within the first 15 min (Fig. 11). Although much of the inhibitory effect of $3 \mu \mathrm{M}$ auranofin appeared to be indirect, as shown by the decrease in fluorescence at $\mathrm{t}=0 \mathrm{hr}$, auranofin also appeared to delay the subsequent increase in fluorescence suggesting a possible inhibitory effect in the cells as well (Fig. 11).

\subsection{PrestoBlue; effects of inhibitors and thiols}

The effects of antioxidant pathway inhibitors on cell viability was first examined by incubating HEK293 cells in 5\% $\mathrm{O}_{2}$ with either BSO and DEM (10 and $100 \mu \mathrm{M}$, respectively), conoidin $\mathrm{A}(10 \mu \mathrm{M})$ or tiopronin $(1 \mathrm{mM})$ for $46 \mathrm{~h}$ in the presence of either AzMC or SSP4 then adding PrestoBlue and measuring PrestoBlue fluorescence one and two hours later (47 and 48h). AzMC and SSP4 fluorescence was monitored at 0,2, 20, 24, 28 and $44 \mathrm{~h}$ to confirm the effects of the inhibitors on $\mathrm{H}_{2} \mathrm{~S}$ and polysulfide production. The effects of the inhibitors on AzMC and SSP4 fluorescence at 0 and $44 \mathrm{~h}$ are shown in Fig. 12 A,C, respectively and PrestoBlue fluorescence in cells is shown in Fig. 12 B,D, respectively and Fig. 12 E shows PrestoBlue fluorescence in PBS. Consistent with previous observations, at $44 \mathrm{~h}$ BSO plus DEM and conoidin A decreased AzMC fluorescence, whereas tiopronin increased it. SSP4 fluorescence was slightly increased by tiopronin, greatly increased ( $\sim 5$ times) by conoidin A and decreased by tiopronin.

With the PrestoBlue method cell viability is determined by the reduction of the nonfluorescent resazurin to fluorescent resorufin, which purportedly occurs in the reducing 
environment of live cells but not in the more oxidizing environment of dead ones [61]. In AzMC-treated cells, Prestoblue fluorescence was greater in the control cells than it was in PBS after $1 \mathrm{~h}$ incubation and fluorescence increased further in the cells but not in PBS at hour two. This indicates that the HEK293 cells are still viable after $48 \mathrm{~h}$ in $5 \% \mathrm{O}_{2}$. In AzMC-treated cells, both BSO plus DEM and tiopronin produced a further increase in PrestoBlue fluorescence compared to control cells, whereas fluorescence was decreased by conoidin A after $2 \mathrm{~h}$ incubation. Prestoblue fluorescence in all SSP4-treated cells was not significantly different from that in PBS.

AzMC, SSP4, $\mathrm{H}_{2} \mathrm{~S}$ (as $\mathrm{Na}_{2} \mathrm{~S}$ ) or mixed polysulfides (as $\mathrm{K}_{2} \mathrm{~S}_{\mathrm{n}}, \mathrm{n}=1-7$ ) were then incubated with PrestoBlue in PBS in order to determine they directly affected PrestoBlue fluorescence. As shown in Fig. S11, neither AzMC nor SSP4 directly affected PrestoBlue fluorescence, whereas $\mathrm{Na}_{2} \mathrm{~S}$ doubled PrestoBlue fluorescence by $30 \mathrm{~min}$ and $\mathrm{K}_{2} \mathrm{~S}_{\mathrm{n}}$ immediately increased fluorescence by over 13 fold. Incubation of $\mathrm{Na}_{2} \mathrm{~S}$ with $\mathrm{AzMC}$ or of $\mathrm{K}_{2} \mathrm{~S}_{\mathrm{n}}$ with SSP4 for one hour prior to addition of Prestoblue eliminated most of the effect of these sulfides on Prestoblue fluorescence.

\subsection{Verification of AzMC specificity}

The effects of GSH, 3-MP, $\mathrm{H}_{2} \mathrm{O}_{2}$ and the NO donor sodium nitroprusside on AzMC fluorescence in PBS are shown in Fig. S13A. None of these compounds, even at the highest concentrations, had any appreciable effect on AzMC fluorescence compared to $\mathrm{H}_{2} \mathrm{~S}$. 
AzMC fluorescence increased in HEK293 cells over $48 \mathrm{~h}$ and this was slightly, but significantly $(p<0.05)$ inhibited by AOA+PPG at $48 \mathrm{~h}$. Hypoxia greatly increased AzMC fluorescence and this was inhibited by AOA+PPG at both 24 and $48 \mathrm{~h}$ (Fig. S13B). These results indicate that AzMC fluorescence reflects cellular $\mathrm{H}_{2} \mathrm{~S}$ production because inhibitors of $\mathrm{H}_{2} \mathrm{~S}$ biosynthesis produced the expected decrease in fluorescence.

\section{DISCUSSION}

Peroxiredoxin, thioredoxin and glutathione/glutaredoxin antioxidant systems reduce $\mathrm{H}_{2} \mathrm{O}_{2}$ to $\mathrm{H}_{2} \mathrm{O}$ by transfering electrons from NADPH via two or more cysteine relay proteins and GSH, the so-called "thiol switches" [21,62-67]. These processes depend on close apposition of the relay molecules and interference with any component will affect their efficacy. This property explains the general observation that the variety of inhibitors used in the present study increase intracellular $\mathrm{H}_{2} \mathrm{O}_{2}$ and this has been employed in some therapeutic applications, albeit with variable success [22-28,31,59,68-71].

Given the chemical and biological similarities between $\mathrm{H}_{2} \mathrm{O}_{2} / \mathrm{H}_{2} \mathrm{O}$ and $\mathrm{H}_{2} \mathrm{~S}_{2} / \mathrm{H}_{2} \mathrm{~S}$, and the role of cysteine and protein thiols in sulfur metabolism, it seems logical to assume that these antioxidant inhibitors would also uniformly decrease $\mathrm{H}_{2} \mathrm{~S}$ and increase $\mathrm{H}_{2} \mathrm{~S}_{2}$ if they acted via the canonical ROS antioxidant pathways. Failing to observe this (summarized in Table 1), we conclude that these antioxidant systems perform completely different functions with respect to cellular sulfur metabolism and that these may be independent of the ROS-regulating relay switches or they may function in conjunction with heretofore unidentified substrates and enzyme pathways. Our previous observations that catalase, in a NADPH-dependent process, forms $\mathrm{H}_{2} \mathrm{~S}$ from either thioredoxin, or DTT [55] provides a precedent for this hypothesis. 
The 'conventional' and 'unconventional' pathways of $\mathrm{H}_{2} \mathrm{~S}$ and polysulfide metabolism have been summarized in a recent review 72] and provide a convenient starting point for examining the observed effects of ROS antioxidant inhibitors on cellular sulfur metabolism in the present study. $\mathrm{H}_{2} \mathrm{~S}$ production from L-cysteine, and to a lesser extent L-homocysteine, via the actions of cystathionine $\gamma$ lyase (CSE), cystathionine $\beta$ synthase (CBS), and the tandem activities of cysteine amino acid transferase (CAT) and 3-mercaptopyruvate sulfur transferase (3-MST) have been well established as has been $\mathrm{H}_{2} \mathrm{~S}$ production from D-cysteine by D-amino acid oxidase and 3-MST. $\mathrm{H}_{2} \mathrm{~S}$ can also be produced from polysulfides, although this has been less well characterized in cells. Polysulfides are often thought to arise from oxidation of $\mathrm{H}_{2} \mathrm{~S}$ catalyzed by enzymes such as sulfide quinone oxidoreductase and 3-MST, transition metals, heme proteins and uncatalyzed reactions with nitric oxide (NO). CSE and CBS have also been reported to form cysteine per- and polysulfides $\left(\mathrm{CysSS}_{\mathrm{n}} \mathrm{H}\right.$; typically $\left.\mathrm{n}=1-4\right)$ from cystine [73] although this may not be physiologically relevant [74]. Recently, Akaike et al. [74] provided compelling evidence that cysteine is persulfidated and polysulfidated by another, sulfur-donating cysteine in a reaction that is catalyzed by cysteinyl tRNA synthase (CARS). These per- and polysulfide cysteine are co-translationally incorporated into proteins a reaction also catalyzed by CARS. Two CARS, cytoplasmic (CARS1) and mitochondrial (CARS2) are found in eukaryotes with most persulfidation resulting from CARS2, the latter providing the majority of both of mitochondrial as well as cytoplasmic polysulfides. $\mathrm{CysSS}_{\mathrm{n}} \mathrm{H}$ may account for as much as $70-80 \%$ of the protein cysteine and there appears to be a vast interconnected network between polysulfdated proteins and small molecular weight thiols for sulfur signaling, storage and transfer $[75,76]$. This large polysulfide network is also apparent in our observation of the rapid and substantial 
increase in SSP4 fluorescence in the present experiments. Several aspects of the actions of the inhibitors used in the present study deserve special attention in this regard.

A number of studies suggest that Trx and 3-MST appear to occupy a unique position at 416 the junction between $\mathrm{H}_{2} \mathrm{~S}$ /polysulfide metabolism and antioxidant pathways. As we have shown 417 catalase catalyzed the production of $\mathrm{H}_{2} \mathrm{~S}$ in the presence of NADPH [55]. It has also been shown 418 that Trx releases $\mathrm{H}_{2} \mathrm{~S}$ from 3MP-persulfidated 3-MST [77] and both $\mathrm{H}_{2} \mathrm{~S}$ and polysulfides are 419 released from a 3-MST tri-sulfide that is formed when thiosulfate reacts with 3-MST [78]. 420 Reduced Trx also cleaves the intersubunit Cys-Cys bond of an oxidized, inactivated 3-MST 421 dimer thereby reactivating the enzyme [79]. In the brain, 3-MST produces a variety of cysteine and glutathione per- and polysulfides as well as $\mathrm{H}_{2} \mathrm{~S}$ and $\mathrm{H}_{2} \mathrm{~S}_{n}[80,81]$ and the persulfide concentration has been reported to be nearly equal to the concentration of $\mathrm{H}_{2} \mathrm{~S}[82,83]$. Germane to the present study, it has recently been shown that exogenous $\mathrm{H}_{2} \mathrm{~S}$ prevents $\mathrm{H}_{2} \mathrm{O}_{2}$-induced cell death in cells treated with auranofin, which was presumed to inhibit Trx. These studies also showed that $\mathrm{H}_{2} \mathrm{~S}$ didn't affect Trx ptotein levels but favored dissociation of Trx from the endogenous thioredoxin inhibitor, TXNIP (thioredoxin-interacting protein; [84]. See also

\subsection{BSO and DEM}

Glutathione (GSH) is at the center of cellular redox balance, both as a the most prevalent intracellular ROS buffer and as an intermediary in the GSH/glutaredoxin antioxidant system [62]. Both BSO and DEM decrease intracellular GSH over 24 hrs in primary cortical cultures 
intracellular cysteine, decreases cystine uptake and increases oxidative stress [57,70]. DEM directly conjugates to GSH which lowers intracellular cysteine and stimulates cystine uptake. DEM may [68] or may not [57] increase oxidative stress.

Despite the opposite effects of BSO and DEM on intracellular cysteine, both inhibitors 440 decreased intracellular $\mathrm{H}_{2} \mathrm{~S}$ without affecting polysulfides. Although we used different cells than 441 those examined by Albano et al. [57], our results suggests that of BSO and DEM have the same 442 effects in HEK293 cells then perhaps as much as half of the $\mathrm{H}_{2} \mathrm{~S}$ production in HEK293 cells is 443 derived from a sulfur moiety other than cysteine. This is supported by our recent observations 444 that inhibiting CSE, CBS and 3-MST with drugs or by siRNA only decreases cellular $\mathrm{H}_{2} \mathrm{~S}$ 445 production by half (Olson et al., in review). Evidence that the inhibitory effects of BSO and DEM on $\mathrm{H}_{2} \mathrm{~S}$ are mediated via GSH is further supported by the relatively rapid inhibitory effect of DEM compared to BSO (Fig. 10) which we interpret as the immediate lowering of GSH due to DEM binding compared to BSO which inhibits GSH synthesis but does not directly remove affect GSH.

It is possible that $\mathrm{H}_{2} \mathrm{~S}$ is derived directly from GSH or that GSH mediates some transsulfuration process with another polysulfide than then releases $\mathrm{H}_{2} \mathrm{~S}$. The identity of this peror polysulfide is unknown. However, it is doubtful that this is cystine. Cystine does not appear to be a source of $\mathrm{H}_{2} \mathrm{~S}$ in HEK293 cells [74] and we showed that it actually decreased intracellular $\mathrm{H}_{2} \mathrm{~S}$ (Fig. 2). Furthermore, the cystine effect cannot be indirect as it slightly increased both AzMC and SSP4 fluorescence in buffer (Fig S3). The inability of exogenous cystine to affect BSO- and DEM-induced reduction in intracellular $\mathrm{H}_{2} \mathrm{~S}$, despite the fact that DEM increases 
supports the hypothesis that these compounds do not act through an indirect effect on cellular

$459 \quad$ cysteine or cystine.

\subsection{Auranofin}

Auranofin is an irreversible inhibitor of the seleno-antioxidant enzymes, glutathione reductase and thioredoxin reductase $[27,58,59]$. Auranofin, like BSO and DEM, increases ROS in cells and in our studies it decreased AzMC fluorescence, as did BSO and DEM (Fig. 3). Unlike BSO or DEM, auranofin also decreased SSP4 fluorescence (Fig. 3). This latter effect could be attributable to a direct effect on the interaction of SSP4 with polysulfides as auranofin inhibited the reaction of SSP4 with $\mathrm{K}_{2} \mathrm{~S}_{\mathrm{n}}$ to the same extent (Fig. S5), although if SSP4 was administered to HEK293 cells several days after auranofin there was an increase in polysulfides suggesting a rebound from an initial inhibition of polysulfide production (Fig. 4). Both AzMC and SSP4 are irreversible RSS fluorophores and provide a history of the amount of RSS produced not the current concentration. By adding SSP4 on consecutive days after auranofin, BSO and DEM, as we did in Fig. 4, we were able to follow polysulfide production at different

\subsection{Conoidin A}


specific effects on polysulfide metabolism. As conoidin A is a covalent inhibitor of peroxiredoxin [60], our results implicate peroxiredoxins in polysulfide metabolism.

Peroxiredoxins are ubiquitously distributed in eukaryotes and well known for their ability to scavenge as much as $90 \%$ of intracellular $\mathrm{H}_{2} \mathrm{O}_{2}$. Recent evidence suggests that they also play of ROS [88]. key roles in $\mathrm{H}_{2} \mathrm{O}_{2}$ signaling [64-66]. Like the other antioxidants examined in our study, peroxiredoxins employ cysteine redox switches. As eloquently discussed by Stöcker et al. [66], the conundrum of $\mathrm{H}_{2} \mathrm{O}_{2}$ signaling is the fact that peroxisomes are far more prevalent in cells and have a much greater affinity for $\mathrm{H}_{2} \mathrm{O}_{2}$ than do the putative target thiols of regulatory proteins. So the question becomes, how can $\mathrm{H}_{2} \mathrm{O}_{2}$ selectively react with the appropriate target? Stöcker et al. [66] offer two possibilities, in the first, two-step relay, the $\mathrm{H}_{2} \mathrm{O}_{2}$-oxidized peroxidase oxidizes an intermediary oxidoreductase which then acts as a relay between the initial peroxidase and target protein. In the second one-step mechanism the peroxidase forms a complex with the target protein and the oxidizing equivalents are transferred directly from the peroxidase to the target. Spatial constraints in the site(s) of oxidant production and effector receptivity can convey additional specificity. Our results suggest a third signaling possibility, $\mathrm{H}_{2} \mathrm{~S}$, which is produced in response to a stressor, e.g., hypoxia [87], is oxidized by peroxiredoxins to a polysulfide which then persulfidates the cysteine of the regulatory protein. This mechanism may resolve another conundrum, that being the identity of the oxygen sensor by supporting RSS via $\mathrm{H}_{2} \mathrm{~S}$ [87] in favor

\subsection{Tiopronin}

Glutathione peroxidases (GPx) are a family of selenocysteine-containing enzymes that catalytically degrade $\mathrm{H}_{2} \mathrm{O}_{2}$ consuming two GSH and in the process generating oxidized 
glutathione (GSSG) and $\mathrm{H}_{2} \mathrm{O}$. Tiopronin is a reversible glutathione peroxidase inhibitor believed to exert biological activity in part by ROS scavenging mediated by its thiol group $[25,89,90]$. Given that GPx consumes GSH it seems likely that tiopronin would increase GSH if GPx was actively metabolizing $\mathrm{H}_{2} \mathrm{O}_{2}$. We observed that tiopronin produced a profound increase in intracellular $\mathrm{H}_{2} \mathrm{~S}$ (Figs. 6, 10) that could not be attributed to a direct effect of tiopronin on interactions between AzMC, $\mathrm{H}_{2} \mathrm{~S}$ and tiopronin, all of which tended to decrease AzMC fluorescence (Fig. S7). These results support, albeit in a correlational context, the role of GSH in $\mathrm{H}_{2} \mathrm{~S}$ production; tiporonin increases GSH and $\mathrm{H}_{2} \mathrm{~S}$ while BSE and DEM decrease GSH and $\mathrm{H}_{2} \mathrm{~S}$

\subsection{Avoiding artifacts; interference, interactions and other considerations}

Most analytical methodologies are developed with consideration for specificity regarding analytes with chemical similarities, whereas other potential artifacts are less commonly identified. These pitfalls have been pointed out with respect to ROS [91,92]. We also considered the possibility that fluorophores (and an amperometric $\mathrm{H}_{2} \mathrm{O}_{2}$ electrode) that were designed to measure ROS also detected RSS and showed that this indeed was the case. Two of these, the redox-sensitive green fluorescent protein, roGFP and the $\mathrm{H}_{2} \mathrm{O}_{2}$ electrode, were actually far more sensitive to RSS than they were to ROS [41]. Fortunately for the present study, neither AzMC nor SSP4 appear to react with $\mathrm{H}_{2} \mathrm{O}_{2}$, the NO donor diethylamine NONOate or the free radical dipotassium nitrosodisulfonate (Fremy's salt) and AzMC does not react with polysulfides and SSP4 does not react with $\mathrm{H}_{2} \mathrm{~S}$ [93]. However, Bibli et al. also reported that AzMC was approximately 4.6, 3.6 and 2.5 times more sensitive to Cys, 3-MP and GSH, respectively than it was to $\mathrm{H}_{2} \mathrm{~S}$ [93]. We did not observe this dramatic of an effect of Cys, which only increased 
AzMC fluorescence by less than 15\% (Fig. S3A). Nor did we observe any appreciable effect of GSH, 3-MP, $\mathrm{H}_{2} \mathrm{O}_{2}$ or the NO-donor sodium nitroprusside on AzMC fluorescence (Fig. S13A) suggesting that these compounds do not interfere with $\mathrm{H}_{2} \mathrm{~S}$-mediated AzMC fluorescence.

530 Furthermore, we also observed that inhibitors of $\mathrm{H}_{2} \mathrm{~S}$ biosynthesis also inhibited AzMC

531 fluorescence in HEK293 cells indicating that AzMC is an effective probe of cellular $\mathrm{H}_{2} \mathrm{~S}$

532 production. While these do not encompass all possible ROS or RSS, we can at least rule out a 533 few of the more probable interfering molecules.

In the present study we looked for three other potential problems, reactions between the fluorophores and inhibitors (left panels in Figs. S1-S10), reactions between the inhibitors and RSS (middle panels in Figs. S1-S10) and optical quenching or other interference of the RSSactivated fluorophore by the inhibitors (right panels in Figs. S1-S10). These experiments showed potential problems with a number of inhibitors that could affect interpretation of their effects on RSS in cells. Conoidin A appeared to interfere with both AzMC and SSP4 fluorescence (Fig. S6) which obviated definitive conclusions of its effect on cellular $\mathrm{H}_{2} \mathrm{~S}$ metabolism but not on polysulfide production as it increased SSP4 fluorescence in cells. Tiopronin also interfered with AzMC and SSP4 fluorescence in buffer (Fig. S7) but produced the opposite response in cellular AzMC fluorescence suggesting it too had a direct effect on cellular $\mathrm{H}_{2} \mathrm{~S}$ production. 2-AAPA appeared to directly react with SSP4 (Fig. S9), while ebselen appeared to catalyze $\mathrm{H}_{2} \mathrm{~S}$ oxidation to polysulfides which resulted in a decrease in AzMC fluorescence and an increase in SSP4 fluorescence (Fig. S8). It was not possible to ascertain if either 2-AAPA or ebselen affected cellular RSS. Nor can we conclude that $\mathrm{H}_{2} \mathrm{~S}$ and polysulfides

8
are the only RSS affected by these inhibitors. Sulfenyl cysteine persulfide (Cys-SSOH) has recently been identified [94] that could escape undetected if not reactive with SSP4 as could 
other polysulfoxides [95]. These all need to be resolved as the RSS methodologies are

$551 \quad$ developed.

We have previously shown that a number of metal-centered porphyrins and the porphyrin-containing antioxidant enzyme, catalase, optically interfere with fluorescein-type fluorophores [96] so the effects of the inhibitors in the present study was not entirely unanticipated. We have also shown that a number of the methods used to measure ROS cannot distinguish between ROS and RSS [41]. Most notably, we found that the redox-sensitive green fluorescent protein, roGFP, arguably the gold standard ROS probe [97], is two hundred times more sensitive to RSS than it is to ROS. The redox sensitivity of roGFP is derived from two cysteines inserted into the protein that form an easily reduced disulfide bridge that when oxidized changes the fluorescence absorption spectrum [98]. This clearly explains the responsivity of roGFP to RSS. roGFPs have also been fused with redox catalysts. roGFP fused to peroxiredoxins or Orp1 is reported to provide real time $\mathrm{H}_{2} \mathrm{O}_{2}$ probes [99-101], and when fused with glutaredoxin it is reported to be a very specific probe for the 2 GSH/GSSG redox couple [101]. The sensitivity of all of these modified roGFP probes to RSS will need to be examined before it can be concluded that they are specific for ROS-related events or if they also report

\subsection{Is PrestoBlue a polysulfide probe?}

Reduction of resazurin (PrestoBlue) by the reducing environment in viable cells produces the fluorescent resorufin and is the basis for this assay [61] and our application in the present stidy (Fig. 12). Using this method we showed that HEK293 cells remained viable for up to $48 \mathrm{~h}$ in $5 \% \mathrm{O}_{2}$. We also showed that cells treated with BSO plus DEM, conoidin A or tiopronin also 
reduced Prestoblue suggesting that these inhibitors also did not affect viability. However, conoidin A halved and tiopronin doubled PrestoBlue fluorescence in AzMC-treated cells, whereas an increase in PrestoBlue fluorescence was not observed in cells treated with SSP4. These findings suggest that either, 1) AzMC and/or SSP4 directly affect PrestoBlue fluorescence, 2) SSP4 kills HEK293 cells, or 3) $\mathrm{H}_{2} \mathrm{~S}$ and/or polysulfides reduce resazurin to resorufin. Our evidence of these reactions in buffer (Fig. S11) suggests the latter. First, neither AzMC nor SSP4 directly affected PrestoBlue fluorescence. Second, if SSP4 killed the cells then we would not expect to see SSP4 fluorescence increase in cells over time nor that this would be differentially sensitive to inhibitors whose effects were shown to be cell-dependent. In the absence of cells, we clearly showed that both $\mathrm{H}_{2} \mathrm{~S}$ and polysulfides reduce PrestoBlue and that polysulfides are far more efficacious in so doing. Figure $\mathbf{S 1 2}$ clearly shows that this is not a general effect of thiols as while DTT and 3MP also reduced PrestoBlue, cysteine and cystine did not. This suggests that endogenous $\mathrm{H}_{2} \mathrm{~S}$, polysulfides or select thiols also are responsible for reducing PrestoBlue in cells. The greater efficacy of polysulfides compared to $\mathrm{H}_{2} \mathrm{~S}$ is likely due to the fact that they are better reductants than $\mathrm{H}_{2} \mathrm{~S}$ [76]. So why does SSP4 prevent any PrestoBlue reduction in cells? We propose that this is due to SSP4 binding to endogenous polysulfides as they are formed before the polysulfides can reduce the Prestoblue. Evidence for this is shown by incubating SSP4 with polysulfides for one hour prior to addition of PrestoBlue which essentially completely inhibits the effect of polysulfides.

Our results also suggested that the mechanism of PrestoBlue reduction in live cells is due, at least in part, to endogenous polysulfides or other thiols. They also suggest the possibility that the supposed oxidation of dead cells which inhibits Prestoblue reduction is not due to increased ROS such as $\mathrm{H}_{2} \mathrm{O}_{2}$ but due to decreased production of persulfide or other thiol. If both conoidin 
A and tiopronin were to increase ROS, as generally assumed (see introduction), then both should have the same effect on PrestoBlue fluorescence, i.e., to decrease it. However, we not only show that these inhibitors have the opposite effects on PrestoBlue fluoresence in cells, but that these effects are identical to their effects on cellular $\mathrm{H}_{2} \mathrm{~S}$. Clearly, additional work is necessary to

600 identify the actual thiols that are responsible for PrestoBlue fluorescence.

\subsection{Summary}

The present experiments suggest that a variety of compounds commonly used to affect

cellular redox balance by inhibiting antioxidant pathways also affect cellular $\mathrm{H}_{2} \mathrm{~S}$ and subsequent secondary effects of these ROS on sulfur metabolism. Rather they suggest that these inhibitors directly affect cellular sulfur metabolism, potentially via established pathways and/or

\section{ACKNOWLEDGMENTS} was supported in part by IUSM BRG grant and by personal funds (KRO). 
615 Table 1. Summary of effects of ROS inhibitors on $\mathrm{H}_{2} \mathrm{~S}$ and polysulfides in HEK293 cells.

\begin{tabular}{|c|c|c|c|c|c|}
\hline Inhibitor & Target & $\mathrm{H}_{2} \mathrm{~S}$ & Polysulfides & Buffer $^{\#}$ & \\
\hline $\mathrm{BSO}$ & $\gamma-\mathrm{GCS}$ & Dec (C-D) & $\mathrm{NC}$ & $\mathrm{NC}$ & $\mathrm{NC}$ \\
\hline DEM & binds GSH & $\operatorname{Dec}(C-D)$ & $\mathrm{NC}$ & $\sqrt{C}$ & $\mathrm{NC}$ \\
\hline Auranofin & GSHR & Dec (C-D) & $\operatorname{Dec}(\mathrm{C}-\mathrm{D})$ & $\mathrm{NC}$ & $\operatorname{Dec}(40)$ \\
\hline Conoidin A & Prx & $\operatorname{Dec}(C-D)^{*}$ & Inc (C-D) & $\operatorname{Dec}(60)$ & $\operatorname{Dec}(40)$ \\
\hline Tiopronin & GPx & $\operatorname{Inc}(C-D)$ & $\mathrm{NC}^{*}$ & $\operatorname{Dec}(35)$ & $\operatorname{Dec}(80)$ \\
\hline 2-AAPA & GSHR, TrxR & $\operatorname{Dec}(C-D)^{*}$ & $\operatorname{Inc}^{*}$ & $\operatorname{Dec}(30)$ & Inc (230) \\
\hline $\mathrm{ADA}$ & CSSC uptake & NC & $\mathrm{NC}$ & $\mathrm{NC}$ & $\operatorname{Dec}(30)$ \\
\hline Ebselen & $\mathrm{H}_{2} \mathrm{O}_{2}$ scavenger & $\operatorname{Dec}(C-D)^{*}$ & Inc* & $\operatorname{Dec}(70)$ & Inc (570) \\
\hline
\end{tabular}

618 Abbreviations; ADA, aminoadipic acid; AzMC, $\mathrm{H}_{2} \mathrm{~S}$ fluorophore; BSO, L-buthionine-

619 sulfoximine; C-D, concentration dependent; CSSC, cystine; Dec, decrease; DEM, diethyl

620 maleate; $\gamma$-GCS, $\gamma$-glutamylcysteine synthase; GSH, glutathione; Gpx, glutathione peroxidase

621 GSHR, glutathione reductase; Grx, glutaredoxin; Inc, increase; NC, no change; Prx,

622 perodiredoxin; Trx, thioredoxin; TrxR, thioredoxin reductase; *, effects may be mediated by 
623 direct interaction with fluorophore or sulfides. \#, only pronounced and consistent effects on 624 AzMC or SSP4 are considered; (maximum percent change) . 


\section{REFERENCES}

[1] N. Brandes, H. Tienson, A. Lindemann, V. Vitvitsky, D. Reichmann, R. Banerjee, U. Jakob, 629 Time line of redox events in aging postmitotic cells, Elife, 2 (2013) e00306.

630 [2] D.I. Brown, K.K. Griendling, Regulation of signal transduction by reactive oxygen species in 631 the cardiovascular system, Circ. Res, 116 (2015) 531-549.

632 [3] Y.R. Chen, J.L. Zweier, Cardiac mitochondria and reactive oxygen species generation, Circ. $633 \quad$ Res, 114 (2014) 524-537.

634 [4] E.T. Chouchani, V.R. Pell, A.M. James, L.M. Work, K. Saeb-Parsy, C. Frezza, T. Krieg, 635 M.P. Murphy, A Unifying Mechanism for Mitochondrial Superoxide Production during 636 Ischemia-Reperfusion Injury, Cell Metab, 23 (2016) 254-263.

637 [5] M.L. Circu, T.Y. Aw, Reactive oxygen species, cellular redox systems, and apoptosis, Free $638 \quad$ Radic. Biol. Med, 48 (2010) 749-762.

639 [6] M.L. Circu, T.Y. Aw, Intestinal redox biology and oxidative stress, Semin. Cell Dev. Biol, 23 $640 \quad$ (2012) 729-737.

641 [7] S.B. Gibson, Investigating the role of reactive oxygen species in regulating autophagy, $642 \quad$ Methods Enzymol, 528 (2013) 217-235.

643 [8] R.L. Goncalves, C.L. Quinlan, I.V. Perevoshchikova, M. Hey-Mogensen, M.D. Brand, Sites 644 of superoxide and hydrogen peroxide production by muscle mitochondria assessed ex vivo under 645 conditions mimicking rest and exercise, J. Biol. Chem, 290 (2015) 209-227.

646 [9] J.D. Lambeth, A.S. Neish, Nox enzymes and new thinking on reactive oxygen: a double647 edged sword revisited, Annu. Rev. Pathol, 9 (2014) 119-145. 
[10] X. Li, P. Fang, J. Mai, E.T. Choi, H. Wang, X.F. Yang, Targeting mitochondrial reactive oxygen species as novel therapy for inflammatory diseases and cancers, Journal of hematology \& oncology, 6 (2013) 19.

[11] K.M. Holmstrom, T. Finkel, Cellular mechanisms and physiological consequences of redoxdependent signalling, Nat. Rev. Mol. Cell Biol, 15 (2014) 411-421.

[12] A. Olschewski, E.K. Weir, Redox Regulation of Ion Channels in the Pulmonary Circulation, Antioxid. Redox. Signal, (2014).

[13] E. Radi, P. Formichi, C. Battisti, A. Federico, Apoptosis and oxidative stress in neurodegenerative diseases, Journal of Alzheimer's disease : JAD, 42 Suppl 3 (2014) S125-152. Biol, 24 (2014) R453-R462.

[15] E. Schulz, P. Wenzel, T. Munzel, A. Daiber, Mitochondrial redox signaling: Interaction of Signal, 20 (2014) 308-324.

[16] K. Sharma, Obesity and Diabetic Kidney Disease: Role of Oxidant Stress and Redox Balance, Antioxidants \& redox signaling, 25 (2016) 208-216.

[17] H. Sies, Hydrogen peroxide as a central redox signaling molecule in physiological oxidative stress: Oxidative eustress, Redox Biol, 11 (2017) 613-619.

[18] H. Sies, C. Berndt, D.P. Jones, Oxidative Stress, Annu Rev Biochem, 86 (2017) 715-748.

[19] C.C. Winterbourn, Are free radicals involved in thiol-based redox signaling?, Free Radic. Biol. Med, 80 (2014) 164-170. 

peroxiredoxin by hydrogen peroxide is critical for thioredoxin-mediated repair of oxidized proteins and cell survival, Mol Cell, 45 (2012) 398-408.

674 [22] L.F. de Souza, A.E. Schmitz, L.C.S. da Silva, K.A. de Oliveira, C.B. Nedel, C.I. Tasca, A.F. 675 de Bem, M. Farina, A.L. Dafre, Inhibition of reductase systems by 2-AAPA modulates 676 peroxiredoxin oxidation and mitochondrial function in A172 glioblastoma cells, Toxicol In 677 Vitro, 42 (2017) 273-280.

678 [23] A. Glasauer, N.S. Chandel, Targeting antioxidants for cancer therapy, Biochemical 679 pharmacology, 92 (2014) 90-101.

680 [24] A. Graczyk-Jarzynka, R. Zagozdzon, A. Muchowicz, M. Siernicka, P. Juszczynski, M. 681 Firczuk, New insights into redox homeostasis as a therapeutic target in B-cell malignancies, Curr 682 Opin Hematol, 24 (2017) 393-401.

683 [25] M.D. Hall, T.S. Marshall, A.D. Kwit, L.M. Miller Jenkins, A.E. Dulcey, J.P. Madigan, K.M. 684 Pluchino, A.S. Goldsborough, K.R. Brimacombe, G.L. Griffiths, M.M. Gottesman, Inhibition of 685 glutathione peroxidase mediates the collateral sensitivity of multidrug-resistant cells to tiopronin, $686 \quad$ J Biol Chem, 289 (2014) 21473-21489.

687 [26] V. Reshetnikov, J. Hahn, C. Maueroder, C. Czegley, L.E. Munoz, M. Herrmann, M.H. 688 Hoffmann, A. Mokhir, Chemical Tools for Targeted Amplification of Reactive Oxygen Species 689 in Neutrophils, Front Immunol, 9 (2018) 1827. 
[27] H.C. May, J.J. Yu, M.N. Guentzel, J.P. Chambers, A.P. Cap, B.P. Arulanandam,

Repurposing Auranofin, Ebselen, and PX-12 as Antimicrobial Agents Targeting the Thioredoxin System, Front Microbiol, 9 (2018) 336.

[28] S.N. Rodman, J.M. Spence, T.J. Ronnfeldt, Y. Zhu, S.R. Solst, R.A. O'Neill, B.G. Allen, X.

Guan, D.R. Spitz, M.A. Fath, Enhancement of Radiation Response in Breast Cancer Stem Cells

by Inhibition of Thioredoxin- and Glutathione-Dependent Metabolism, Radiat Res, 186 (2016) 385-395.

[29] T. Seefeldt, Y. Zhao, W. Chen, A.S. Raza, L. Carlson, J. Herman, A. Stoebner, S. Hanson,

R. Foll, X. Guan, Characterization of a novel dithiocarbamate glutathione reductase inhibitor and its use as a tool to modulate intracellular glutathione, J Biol Chem, 284 (2009) 2729-2737.

[30] Y. Zhao, T. Seefeldt, W. Chen, X. Wang, D. Matthees, Y. Hu, X. Guan, Effects of glutathione reductase inhibition on cellular thiol redox state and related systems, Arch Biochem Biophys, 485 (2009) 56-62.

[31] Y. Zhao, T. Seefeldt, W. Chen, L. Carlson, A. Stoebner, S. Hanson, R. Foll, D.P. Matthees, S. Palakurthi, X. Guan, Increase in thiol oxidative stress via glutathione reductase inhibition as a novel approach to enhance cancer sensitivity to X-ray irradiation, Free Radic Biol Med, 47 (2009) 176-183.

[32] K.R. Olson, K.D. Straub, The Role of Hydrogen Sulfide in Evolution and the Evolution of (2015) 29-59.

[34] V. Gupta, K.S. Carroll, Sulfenic acid chemistry, detection and cellular lifetime, Biochim. Biophys. Acta, 1840 (2014) 847-875. 
[35] H. Kimura, Signaling molecules: hydrogen sulfide and polysulfide, Antioxid. Redox Signal, 22 (2015) 362-376.

[36] C.M. Lo, K.S. Carroll, The redox biochemistry of protein sulfenylation and sulfinylation, J.

716 Biol. Chem, 288 (2013) 26480-26488.

[37] P. Nagy, Mechanistic chemical perspective of hydrogen sulfide signaling, Methods

[38] K. Ono, T. Akaike, T. Sawa, Y. Kumagai, D.A. Wink, D.J. Tantillo, A.J. Hobbs, P. Nagy,

M. Xian, J. Lin, J.M. Fukuto, Redox chemistry and chemical biology of HS, hydropersulfides, and derived species: Implications of their possible biological activity and utility, Free Radic. Biol. Med, 17 (2014) 82-94.

[39] C.C. Winterbourn, Biological Production, Detection, and Fate of Hydrogen Peroxide, Antioxidants \& redox signaling, (2017).

[40] D. Zhang, J. Du, C. Tang, Y. Huang, H. Jin, H2S-Induced Sulfhydration: Biological Function and Detection Methodology, Front Pharmacol, 8 (2017) 608.

[41] E.R. DeLeon, Y. Gao, E. Huang, M. Arif, N. Arora, A. Divietro, S. Patel, K.R. Olson, A case of mistaken identity: are reactive oxygen species actually reactive sulfide species?, Am J Physiol Regul Integr Comp Physiol, 310 (2016) R549-560.

[42] D.P. Jones, H. Sies, The Redox Code, Antioxidants \& redox signaling, 23 (2015) 734-746.

[43] D.V. Dibrova, D.A. Cherepanov, M.Y. Galperin, V.P. Skulachev, A.Y. Mulkidjanian, Evolution of cytochrome bc complexes: from membrane-anchored dehydrogenases of ancient bacteria to triggers of apoptosis in vertebrates, Biochim. Biophys. Acta, 1827 (2013) 1407-1427. [44] S.C. Grace, Phylogenetic distribution of superoxide dismutase supports an endosymbiotic 35 origin for chloroplasts and mitochondria, Life Sci, 47 (1990) 1875-1886. 
[45] E.M. Hanschmann, J.R. Godoy, C. Berndt, C. Hudemann, C.H. Lillig, Thioredoxins, glutaredoxins, and peroxiredoxins--molecular mechanisms and health significance: from cofactors to antioxidants to redox signaling, Antioxid. Redox. Signal, 19 (2013) 1539-1605. [46] M.A. Inupakutika, S. Sengupta, A.R. Devireddy, R.K. Azad, R. Mittler, The evolution of reactive oxygen species metabolism, J Exp Bot, 67 (2016) 5933-5943.

[47] B. Knoops, E. Loumaye, D.E. Van, V, Evolution of the peroxiredoxins, Subcell. Biochem, 44 (2007) 27-40.

[48] J. Lu, A. Holmgren, The thioredoxin antioxidant system, Free Radic. Biol. Med, 66 (2014) 75-87.

[49] A.F. Miller, Superoxide dismutases: ancient enzymes and new insights, FEBS Lett, 586 (2012) 585-595.

[50] S.V. Novoselov, V.N. Gladyshev, Non-animal origin of animal thioredoxin reductases: implications for selenocysteine evolution and evolution of protein function through carboxyterminal extensions, Protein Sci, 12 (2003) 372-378.

[51] X.H. Zhang, H. Weissbach, Origin and evolution of the protein-repairing enzymes methionine sulphoxide reductases, Biol. Rev. Camb. Philos. Soc, 83 (2008) 249-257. [52] D.E. Canfield, K.S. Habicht, B. Thamdrup, The Archean sulfur cycle and the early history of atmospheric oxygen, Science, 288 (2000) 658-661.

[53] S.W. Poulton, P.W. Fralick, D.E. Canfield, The transition to a sulphidic ocean approximately 1.84 billion years ago, Nature, 431 (2004) 173-177. 
[55] K.R. Olson, Y. Gao, E.R. DeLeon, M. Arif, F. Arif, N. Arora, K.D. Straub, Catalase as a sulfide-sulfur oxido-reductase: An ancient (and modern?) regulator of reactive sulfur species (RSS), Redox Biol, 12 (2017) 325-339.

[56] P.M. May, D. Batka, G. Hefter, E. Konigsberger, D. Rowland, Goodbye to S(2-) in aqueous solution, Chem Commun (Camb), 54 (2018) 1980-1983.

[57] R. Albano, N.J. Raddatz, J. Hjelmhaug, D.A. Baker, D. Lobner, Regulation of System xc(-) by Pharmacological Manipulation of Cellular Thiols, Oxid Med Cell Longev, 2015 (2015) 269371.

[58] Y. Ouyang, Y. Peng, J. Li, A. Holmgren, J. Lu, Modulation of thiol-dependent redox system by metal ions via thioredoxin and glutaredoxin systems, Metallomics : integrated biometal science, 10 (2018) 218-228.

[59] F. Radenkovic, O. Holland, J.J. Vanderlelie, A.V. Perkins, Selective inhibition of endogenous antioxidants with Auranofin causes mitochondrial oxidative stress which can be countered by selenium supplementation, Biochemical pharmacology, 146 (2017) 42-52. [60] J.D. Haraldsen, G. Liu, C.H. Botting, J.G. Walton, J. Storm, T.J. Phalen, L.Y. Kwok, D. Soldati-Favre, N.H. Heintz, S. Muller, N.J. Westwood, G.E. Ward, Identification of Conoidin a as a Covalent Inhibitor of Peroxiredoxin Ii, Org Biomol Chem, 7 (2009) 3040-3048. [61] J. O'Brien, I. Wilson, T. Orton, F. Pognan, Investigation of the Alamar Blue (resazurin) fluorescent dye for the assessment of mammalian cell cytotoxicity, Eur J Biochem, 267 (2000) $5421-5426$.

[62] S. Garcia-Santamarina, S. Boronat, E. Hidalgo, Reversible cysteine oxidation in hydrogen peroxide sensing and signal transduction, Biochemistry, 53 (2014) 2560-2580. 
[63] B. Groitl, U. Jakob, Thiol-based redox switches, Biochim Biophys Acta, 1844 (2014) 13351343.

[64] E.C. Ledgerwood, J.W. Marshall, J.F. Weijman, The role of peroxiredoxin 1 in redox sensing and transducing, Arch Biochem Biophys, 617 (2017) 60-67.

[65] A. Perkins, K.J. Nelson, D. Parsonage, L.B. Poole, P.A. Karplus, Peroxiredoxins: guardians

against oxidative stress and modulators of peroxide signaling, Trends Biochem Sci, 40 (2015) $435-445$.

[66] S. Stocker, K. Van Laer, A. Mijuskovic, T.P. Dick, The Conundrum of Hydrogen Peroxide signaling, 28 (2018) 558-573.

[67] C.C. Winterbourn, M.B. Hampton, Redox biology: Signaling via a peroxiredoxin sensor,

[68] S.L. Liao, Y.C. Ou, C.Y. Chang, W.Y. Chen, Y.H. Kuan, W.Y. Wang, H.C. Pan, C.J. Chen, Diethylmaleate and iodoacetate in combination caused profound cell death in astrocytes, $\mathrm{J}$ Neurochem, 127 (2013) 271-282.

[69] A. Markowska, B. Kasprzak, K. Jaszczynska-Nowinka, J. Lubin, J. Markowska, Noble metals in oncology, Contemp Oncol (Pozn), 19 (2015) 271-275.

[70] F. Vargas, I. Rodriguez-Gomez, R. Perez-Abud, P. Vargas Tendero, Y. Baca, R. Wangensteen, Cardiovascular and renal manifestations of glutathione depletion induced by buthionine sulfoximine, Am J Hypertens, 25 (2012) 629-635.

[71] Y. Watanabe, C.E. Murdoch, S. Sano, Y. Ido, M.M. Bachschmid, R.A. Cohen, R. Matsui, Glutathione adducts induced by ischemia and deletion of glutaredoxin-1 stabilize HIF-1alpha and improve limb revascularization, Proc Natl Acad Sci U S A, 113 (2016) 6011-6016. 
[72] K.R. Olson, H2S and polysulfide metabolism: Conventional and unconventional pathways, 805 Biochemical pharmacology, 149 (2018) 77-90.

806 [73] T. Ida, T. Sawa, H. Ihara, Y. Tsuchiya, Y. Watanabe, Y. Kumagai, M. Suematsu, H.

807 Motohashi, S. Fujii, T. Matsunaga, M. Yamamoto, K. Ono, N.O. varie-Baez, M. Xian, J.M.

808 Fukuto, T. Akaike, Reactive cysteine persulfides and S-polythiolation regulate oxidative stress 809 and redox signaling, Proc. Natl. Acad. Sci. U. S. A, (2014).

810 [74] T. Akaike, T. Ida, F.Y. Wei, M. Nishida, Y. Kumagai, M.M. Alam, H. Ihara, T. Sawa, T. 811 Matsunaga, S. Kasamatsu, A. Nishimura, M. Morita, K. Tomizawa, A. Nishimura, S. Watanabe, 812 K. Inaba, H. Shima, N. Tanuma, M. Jung, S. Fujii, Y. Watanabe, M. Ohmuraya, P. Nagy, M. 813 Feelisch, J.M. Fukuto, H. Motohashi, Cysteinyl-tRNA synthetase governs cysteine 814 polysulfidation and mitochondrial bioenergetics, Nat Commun, 8 (2017) 1177.

815 [75] C.L. Bianco, T. Akaike, T. Ida, P. Nagy, V. Bogdandi, J.P. Toscano, Y. Kumagai, C.F. 816 Henderson, R.N. Goddu, J. Lin, J.M. Fukuto, The reaction of hydrogen sulfide with disulfides: 817 formation of a stable trisulfide and implications for biological systems, Br J Pharmacol, (2018). 818 [76] J.M. Fukuto, L.J. Ignarro, P. Nagy, D.A. Wink, C.G. Kevil, M. Feelisch, M.M. Cortese819 Krott, C.L. Bianco, Y. Kumagai, A.J. Hobbs, J. Lin, T. Ida, T. Akaike, Biological 820 hydropersulfides and related polysulfides - a new concept and perspective in redox biology, $821 \quad$ FEBS Lett, 592 (2018) 2140-2152.

822 [77] Y. Mikami, N. Shibuya, Y. Kimura, N. Nagahara, Y. Ogasawara, H. Kimura, Thioredoxin 823 and dihydrolipoic acid are required for 3-mercaptopyruvate sulfurtransferase to produce 824 hydrogen sulfide, Biochem. J, 439 (2011) 479-485. 
[78] N. Nagahara, S. Koike, T. Nirasawa, H. Kimura, Y. Ogasawara, Alternative pathway of $\mathrm{H} 2 \mathrm{~S}$ and polysulfides production from sulfurated catalytic-cysteine of reaction intermediates of 3-mercaptopyruvate sulfurtransferase, Biochem Biophys Res Commun, 496 (2018) 648-653. activation of mercaptopyruvate sulfurtransferase. An intersubunit disulfide bond serves as a redox switch for activation, J. Biol. Chem, 282 (2007) 1561-1569. [80] Y. Kimura, Y. Toyofuku, S. Koike, N. Shibuya, N. Nagahara, D. Lefer, Y. Ogasawara, H. Kimura, Identification of $\mathrm{H} 2 \mathrm{~S} 3$ and $\mathrm{H} 2 \mathrm{~S}$ produced by 3-mercaptopyruvate sulfurtransferase in the brain, Sci Rep, 5 (2015) 14774. sulfurtransferase produces potential redox regulators cysteine- and glutathione-persulfide (CysSSH and GSSH) together with signaling molecules H2S2, H2S3 and H2S, Sci Rep, 7 (2017) 10459.

[82] S. Koike, K. Kawamura, Y. Kimura, N. Shibuya, H. Kimura, Y. Ogasawara, Analysis of endogenous $\mathrm{H} 2 \mathrm{~S}$ and $\mathrm{H} 2 \mathrm{Sn}$ in mouse brain by high-performance liquid chromatography with fluorescence and tandem mass spectrometric detection, Free Radic Biol Med, 113 (2017) 355362.

[83] S. Koike, S. Nishimoto, Y. Ogasawara, Cysteine persulfides and polysulfides produced by exchange reactions with $\mathrm{H} 2 \mathrm{~S}$ protect SH-SY5Y cells from methylglyoxal-induced toxicity through Nrf2 activation, Redox Biol, 12 (2017) 530-539.

[84] Z. Mao, Y. Huang, Z. Zhang, X. Yang, X. Zhang, Y. Huang, N. Sawada, T. Mitsui, M. Takeda, J. Yao, Pharmacological levels of hydrogen sulfide inhibit oxidative cell injury through regulating the redox state of thioredoxin, Free Radic Biol Med, 134 (2019) 190-199. 
[85] H. Kimura, Hydrogen polysulfide (H2S n ) signaling along with hydrogen sulfide (H2S) and nitric oxide (NO), J Neural Transm (Vienna), 123 (2016) 1235-1245.

[86] K. Hosoya, M. Tomi, S. Ohtsuki, H. Takanaga, S. Saeki, Y. Kanai, H. Endou, M. Naito, T.

Tsuruo, T. Terasaki, Enhancement of L-cystine transport activity and its relation to $\mathrm{xCT}$ gene induction at the blood-brain barrier by diethyl maleate treatment, J Pharmacol Exp Ther, 302 (2002) 225-231.

[87] K.R. Olson, Hydrogen sulfide as an oxygen sensor, Antioxidants \& redox signaling, 22 (2015) 377-397.

[88] J.T. Sylvester, L.A. Shimoda, P.I. Aaronson, J.P. Ward, Hypoxic pulmonary vasoconstriction, Physiol Rev, 92 (2012) 367-520.

[89] J. Chaudiere, E.C. Wilhelmsen, A.L. Tappel, Mechanism of selenium-glutathione peroxidase and its inhibition by mercaptocarboxylic acids and other mercaptans, J Biol Chem, 259 (1984) 1043-1050.

[90] A.S. Goldsborough, M.D. Handley, A.E. Dulcey, K.M. Pluchino, P. Kannan, K.R.

Brimacombe, M.D. Hall, G. Griffiths, M.M. Gottesman, Collateral sensitivity of multidrugresistant cells to the orphan drug tiopronin, J Med Chem, 54 (2011) 4987-4997.

[91] H.J. Forman, O. Augusto, R. Brigelius-Flohe, P.A. Dennery, B. Kalyanaraman, H. Ischiropoulos, G.E. Mann, R. Radi, L.J. Roberts, J. Vina, K.J. Davies, Even free radicals should follow some rules: A Guide to free radical research terminology and methodology, Free Radic. Biol. Med, 78 (2015) 233-235.

[92] B. Kalyanaraman, V. rley-Usmar, K.J. Davies, P.A. Dennery, H.J. Forman, M.B. Grisham, G.E. Mann, K. Moore, L.J. Roberts, H. Ischiropoulos, Measuring reactive oxygen and nitrogen 
species with fluorescent probes: challenges and limitations, Free Radic. Biol. Med, 52 (2012) 1-

6.

[93] S.I. Bibli, B. Luck, S. Zukunft, J. Wittig, W. Chen, M. Xian, A. Papapetropoulos, J. Hu, I.

873 Fleming, A selective and sensitive method for quantification of endogenous polysulfide

874 production in biological samples, Redox Biol, 18 (2018) 295-304.

[94] D.E. Heppner, M. Hristova, T. Ida, A. Mijuskovic, C.M. Dustin, V. Bogdandi, J.M. Fukuto,

T.P. Dick, P. Nagy, J. Li, T. Akaike, A. van der Vliet, Cysteine perthiosulfenic acid (Cys-

SSOH): A novel intermediate in thiol-based redox signaling?, Redox Biol, 14 (2018) 379-385.

[95] J.I. Toohey, A.J. Cooper, Thiosulfoxide (sulfane) sulfur: new chemistry and new regulatory roles in biology, Molecules, 19 (2014) 12789-12813.

[96] K.R. Olson, Y. Gao, F. Arif, K. Arora, S. Patel, E. DeLeon, K.D. Straub, Fluorescence quenching by metal centered porphyrins and poryphyrin enzymes, Am J Physiol Regul Integr Comp Physiol, 313 (2017) R340-R346.

[97] M. Schwarzlander, T.P. Dick, A.J. Meye, B. Morgan, Dissecting Redox Biology using Fluorescent Protein Sensors, Antioxid. Redox Signal, (2015).

[98] M.B. Cannon, S.J. Remington, Redox-sensitive green fluorescent protein: probes for dynamic intracellular redox responses. A review, Methods Mol. Biol, 476 (2008) 51-65.

[99] M. Gutscher, M.C. Sobotta, G.H. Wabnitz, S. Ballikaya, A.J. Meyer, Y. Samstag, T.P. Dick,

Proximity-based protein thiol oxidation by $\mathrm{H} 2 \mathrm{O} 2$-scavenging peroxidases, J. Biol. Chem, 284 (2009) 31532-31540.

[100] B. Morgan, K. Van Laer, T.N. Owusu, D. Ezerina, D. Pastor-Flores, P.S. Amponsah, A. Tursch, T.P. Dick, Real-time monitoring of basal H2O2 levels with peroxiredoxin-based probes, Nat Chem Biol, 12 (2016) 437-443. 
893 [101] M. Gutscher, A.L. Pauleau, L. Marty, T. Brach, G.H. Wabnitz, Y. Samstag, A.J. Meyer, 894 T.P. Dick, Real-time imaging of the intracellular glutathione redox potential, Nat. Methods, 5 $895 \quad$ (2008) 553-559.

896 


\section{FIGURE CAPTIONS}

899 Figure 1. Concentration-dependent inhibitory effects of BSO and DEM on AzMC fluorescence 900 in HEK293 cells in either normoxia $\left(21 \% \mathrm{O}_{2}\right)$ or hypoxia $\left(5 \% \mathrm{O}_{2}\right)$ and effects of $10 \mu \mathrm{M}$ BSO or $901100 \mu \mathrm{M}$ DEM on SSP4 fluorescence in HEK293 cells (right panels). Mean $+\mathrm{SE}, \mathrm{n}=8$ wells all 902 experiments.

903

904 Figure 2. Effects of $10 \mu \mathrm{M}$ BSO and $100 \mu \mathrm{M}$ DEM with or without $200 \mu \mathrm{M}$ cystine on AzMC 905 and SSP4 fluorescence in normoxic HEK293 cells. Cystine alone decreased AzMC fluorescence 906 but did not significantly affect the greater inhibitory effects of either BSO or DEM on AzMC 907 fluorescence. SSP4 fluorscence was unaffected by cystine, BSO, DEM, alone or in combination. 908 Mean $+\mathrm{SE}, \mathrm{n}=8$ wells all experiments.

910 Figure 3. Auranofin concentration-dependently inhibits AzMC and SSP4 fluorescence in 911 HEK293 cells in both normoxia $\left(21 \% \mathrm{O}_{2}\right)$ or hypoxia $\left(5 \% \mathrm{O}_{2}\right)$. Mean $+\mathrm{SE}, \mathrm{n}=8$ wells all 912 experiments.

914 Figure 4. Effects of $10 \mu \mathrm{M}$ BSO plus $100 \mu \mathrm{M}$ DEM and either 3 or $10 \mu \mathrm{M}$ auranofin on 915 intracellular AzMC and SSP4 fluorescence in HEK293 cells. BSO, DEM and auranofin were 916 added to all wells at day 1 and AzMC added to separate wells at days 1, 2 and 3 and SSP4 added 917 at day 1,2,3 and 4. AzMC fluorescence was inhibited throughout the experimental period, 918 whereas SSP4 fluorescence was inhibited at day 1 but by day 2-3 this was reversed and there was 919 more fluorescence in the inhibited cells. Mean + SE, $n=8$ wells all experiments. 
921 Figure 5. Conoidin A concentration-dependently decreases intracellular AzMC fluorescence 922 and increases SSP4 fluorescence in both normoxic and hypoxic HEK293 cells. Mean +SE, n=8 923 wells all experiments.

Figure 6. Tiopronin concentration-dependently increases intracellular AzMC fluorescence in normoxic HEK293 cells and this was further increased in hypoxic cells. After $21 \mathrm{~h} \mathrm{AzMC}$ fluorescence progressively declined in hypoxic cells but continued to rise, albeit slightly in normoxic cells. SSP4 fluorescence was decreased by tiopronin in both environments with the most notable response in hypoxic cells treated with $1 \mathrm{mM}$. Mean $+\mathrm{SE}, \mathrm{n}=8$ wells all experiments.

Figure 7. Ebselen concentration-dependently decreases intracellular AzMC fluorescence in 933 normoxic and hypoxic HEK293 cells but has minimal effects on SSP4 fluorescence with the 934 exception of a delayed increase in fluorescence. Mean + SE, $n=8$ wells all experiments.

Figure 8. 2-AAPA concentration- and time-dependently decreases intracellular AzMC fluorescence but profoundly, and immediately, increases SSP4 fluorescence in both normoxic and hypoxic HEK293 cells. Mean + SE, n=8 wells all experiments.

Figure 9. Aminoadipic acid does not affect AzMC or SSP4 fluorescence in either normoxic or hypoxic HEK293 cells. Mean + SE, n=8 wells all experiments. 
942 Figure 10. Short-term effects of BSO, DEM, tiopronin and conoidin A on AzMC fluorescence 943 in HEK293 cells. Mean + SE, $n=8$ wells all experiments.

944 Figure 11. Short-term effects of conoidin A and auranofin on SSP4 fluorescence in HEK293 945 cells. Mean $+\mathrm{SE}, \mathrm{n}=8$ wells all experiments.

947 Figure 12. Effects of BSO plus DEM (10 and $100 \mu \mathrm{M}$, respectively), conoidin $\mathrm{A}(10 \mu \mathrm{M})$ and 948 tiopronin $(1 \mathrm{mM})$ on AzMC (A) and SSP4 (C) fluorescence at 0 and $44 \mathrm{hr}$ and on PrestoBlue 949 fluorescence in AzMC (B) and SSP4 (D) treated cells $1 \mathrm{~h}$ and $2 \mathrm{~h}$ after addition of PrestoBlue 950 (hours 47 and 48 after start of experiment). (E) PrestoBlue fluorescence after 1 and $2 \mathrm{~h}$ in 951 phosphate buffered saline (PBS). Mean + SE, n=8 wells all experiments; *, significantly $952 \quad(p<0.005)$ different from respective control; \#, PrestoBlue fluorescence of SSP4-treated cells 953 significantly $(p<0.005)$ different from PrestoBlue in PBS; PrestoBlue fluorescence of all AzMC954 treated cells was significantly $(p<0.05)$ different from PBS.S 
956 Supplementary information

\section{Polysulfide Metabolism}

960

961 Kenneth R. Olson ${ }^{\mathrm{a}, \mathrm{b}}$ and Yan Gao

962 a. Indiana University School of Medicine - South Bend Center, South Bend, Indiana 46617 USA

963 b. Department of Biological Sciences, University of Notre Dame, Notre Dame IN 46556

964

965 Running Head: Antioxidant Inhibitors and RSS Metabolism

966

967

Address correspondence to:

968

Kenneth R. Olson, Ph.D.

969

Indiana University School of Medicine -South Bend

970

Raclin Carmichael Hall

971

1234 Notre Dame Avenue

972

South Bend, IN 46617

973

Phone: (574) 631-7560

974

Fax: (574) 631-7821

975

e-mail: olson.1@nd.edu 


\section{Supplementary Figures}

978 Figures S1-S10. (A, D) direct effects of inhibitors on AzMC and SSP4 fluorescence before 979 addition of inhibitors ( $\mathrm{t}=0 \mathrm{~min})$ and at 10 and $90 \mathrm{~min}$ afterward. (B, E) effects of inhibitors on $980 \quad$ AzMC and SSP4 in the presence of $100 \mu \mathrm{M}(\mathbf{B})$ or $300 \mu \mathrm{M}(\mathbf{E}) \mathrm{H}_{2} \mathrm{~S} . \mathrm{H}_{2} \mathrm{~S}$ and inhibitors were 981 added after $\mathrm{t}=0$ min. $(\mathbf{C}, \mathbf{F})$ effects of inhibitors on fluorescence of AzMC and SSP4 preactivated for 120 min with $30 \mu \mathrm{M} \mathrm{H}_{2} \mathrm{~S}$ or $30 \mu \mathrm{M} \mathrm{K} \mathrm{K}_{2}$, respectively. Mean $+\mathrm{SE}, \mathrm{n}=4$ wells; *, 984

Figure S11. Effects of AzMC, SSP4, $\mathrm{Na}_{2} \mathrm{~S}$ and $\mathrm{K}_{2} \mathrm{~S}_{\mathrm{n}}$ on PrestoBlue (PB) fluorescence in $\mathrm{p}<0.05$ compared to AzMC or SSP4 only at same time.

Figure S12. (A) $\mathrm{K}_{2} \mathrm{~S}_{\mathrm{n}}$ concentration response after $1 \mathrm{~h}$ with PrestoBlue; $\mathrm{X}$ axis numbers $1,2,3$, 4, 5, 6 correspond to 1, 3, 10, 30, 100, $300 \mu \mathrm{M} \mathrm{K} \mathrm{S}_{2}$, respectively. (B) Effects of $300 \mu \mathrm{M}$ each of cysteine (Cys), cystine (CSSC), dithiothreitol (DTT) and 3-mercaptopyruvate (3MP) on Prestoblue florescence as a function of time. Mean $+\mathrm{SE}, \mathrm{n}=4$ wells (buffer) or 8 wells.

Figure S13. (A) Effects of potential interfering molecules on AzMC fluorescence in buffer compared to $\mathrm{H}_{2} \mathrm{~S}$; glutathione (GSH), 3-mercaptopyruvate (3-MP), peroxide $\left(\mathrm{H}_{2} \mathrm{O}_{2}\right)$ and sodium nitroprusside (NP). Mean $+\mathrm{SE}, \mathrm{n}=4$ wells. (B) Inhibitors of $\mathrm{H}_{2} \mathrm{~S}$ biosynthesis, $\mathrm{AOA}+\mathrm{PPG}$ 
999 decrease AzMC fluorescence in HEK293 cells in normoxia (21\% O2) at $48 \mathrm{~h}$ and in hypoxia $1000 \quad\left(5 \% \mathrm{O}_{2}\right)$ at both 24 and $48 \mathrm{~h}$. Mean $+\mathrm{SE}, 8$ wells; * $p<0.05$. 
Fig. 1
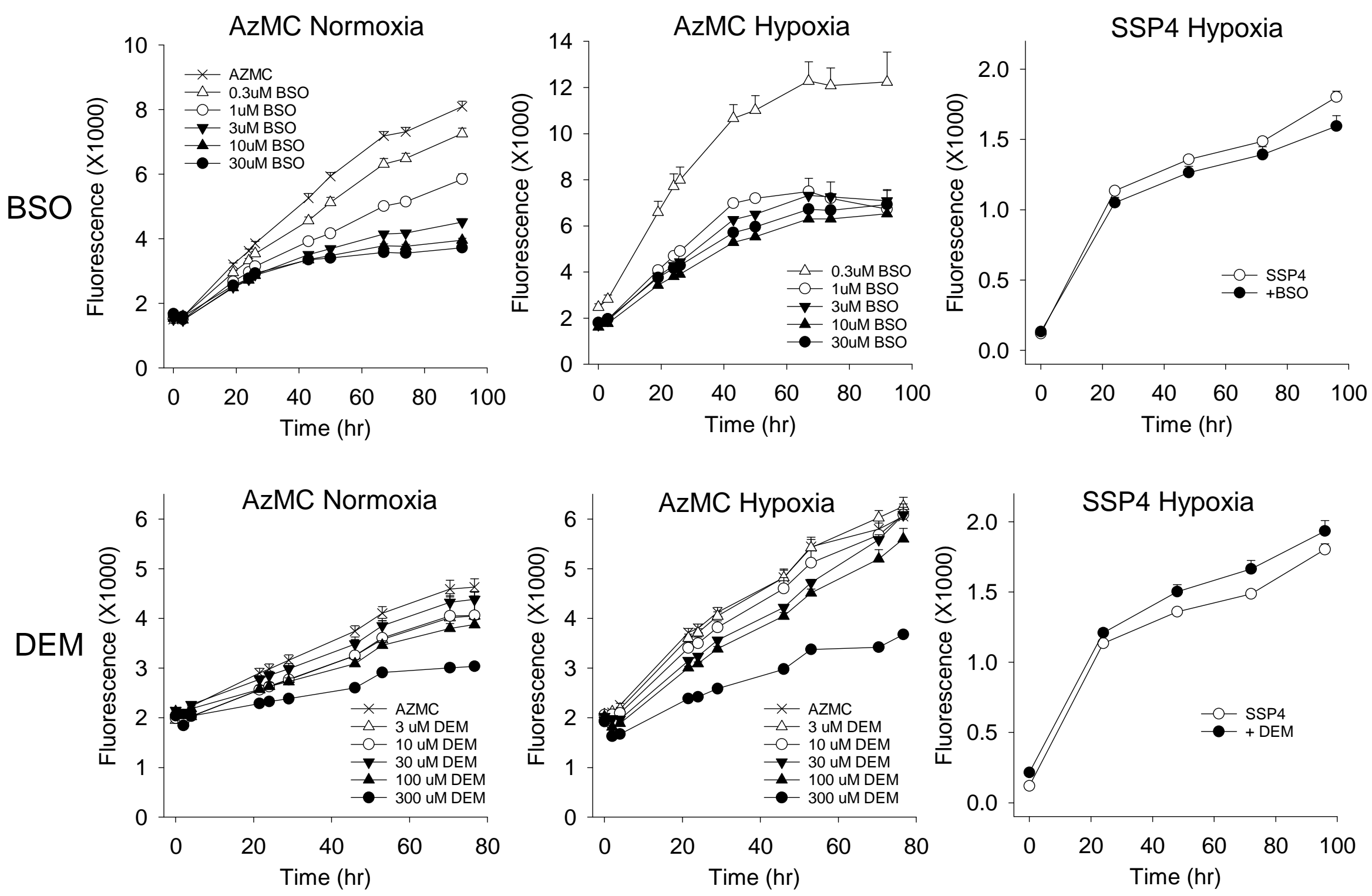
Fig. 2
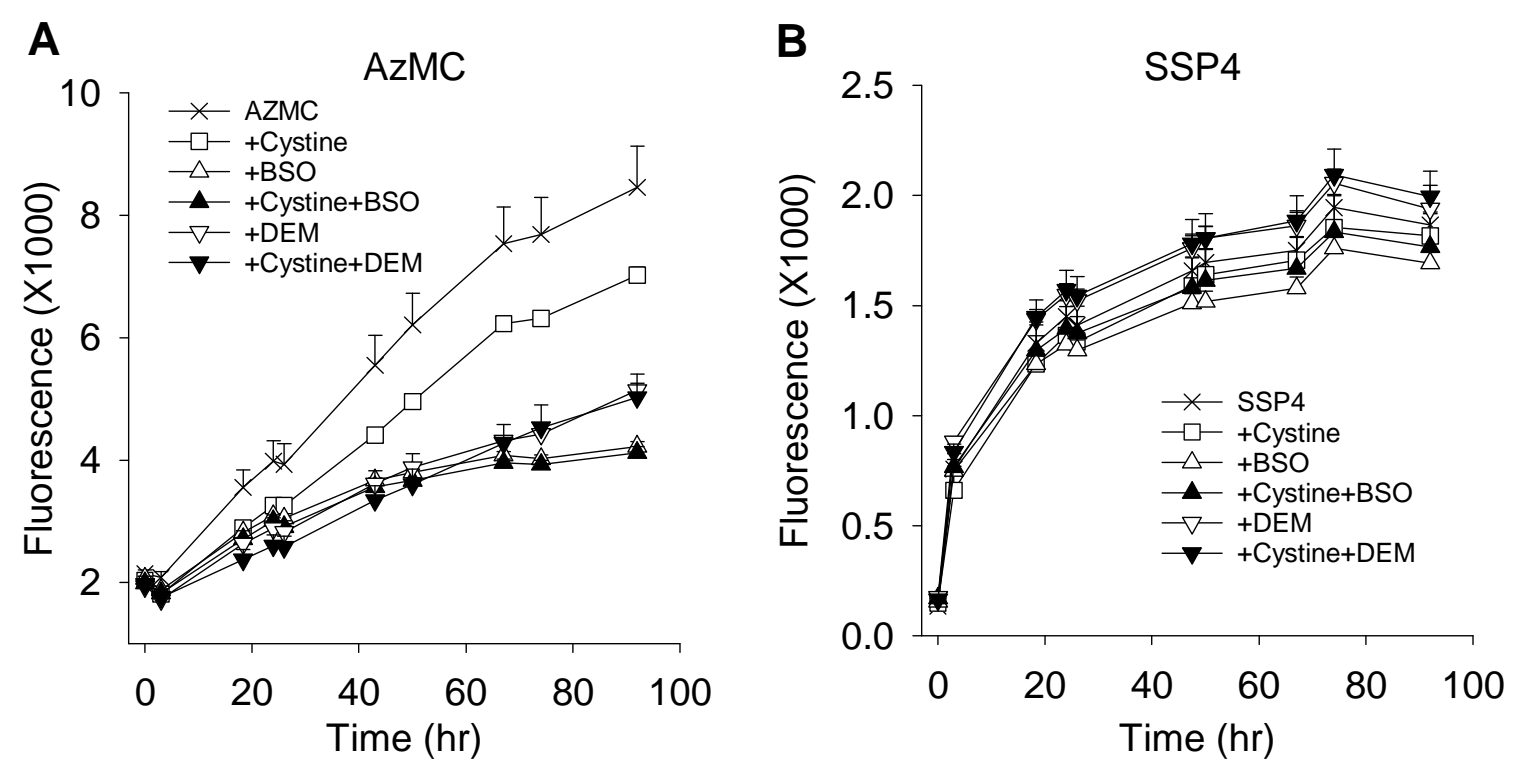
Fig. 3
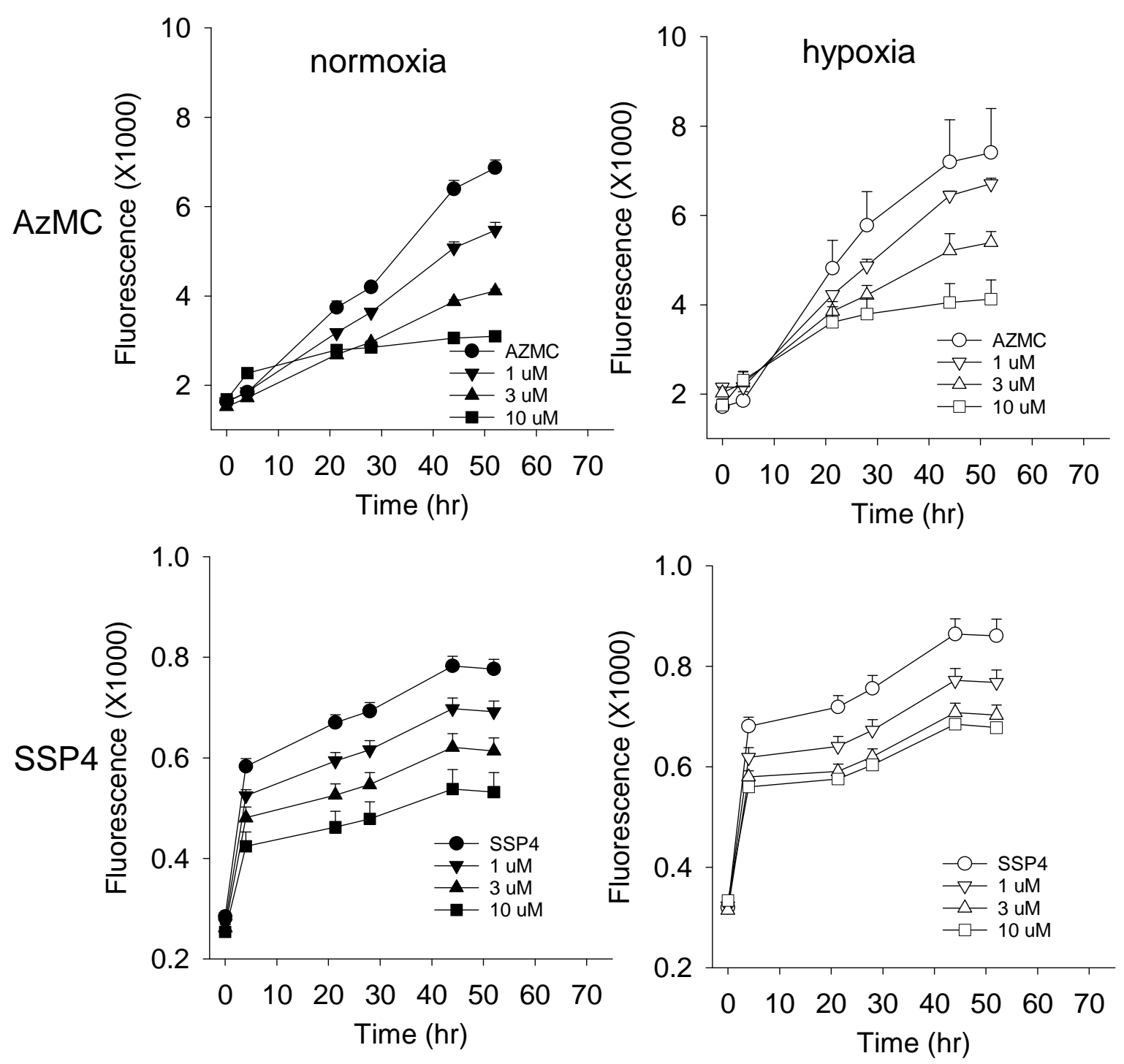
Fig. 4
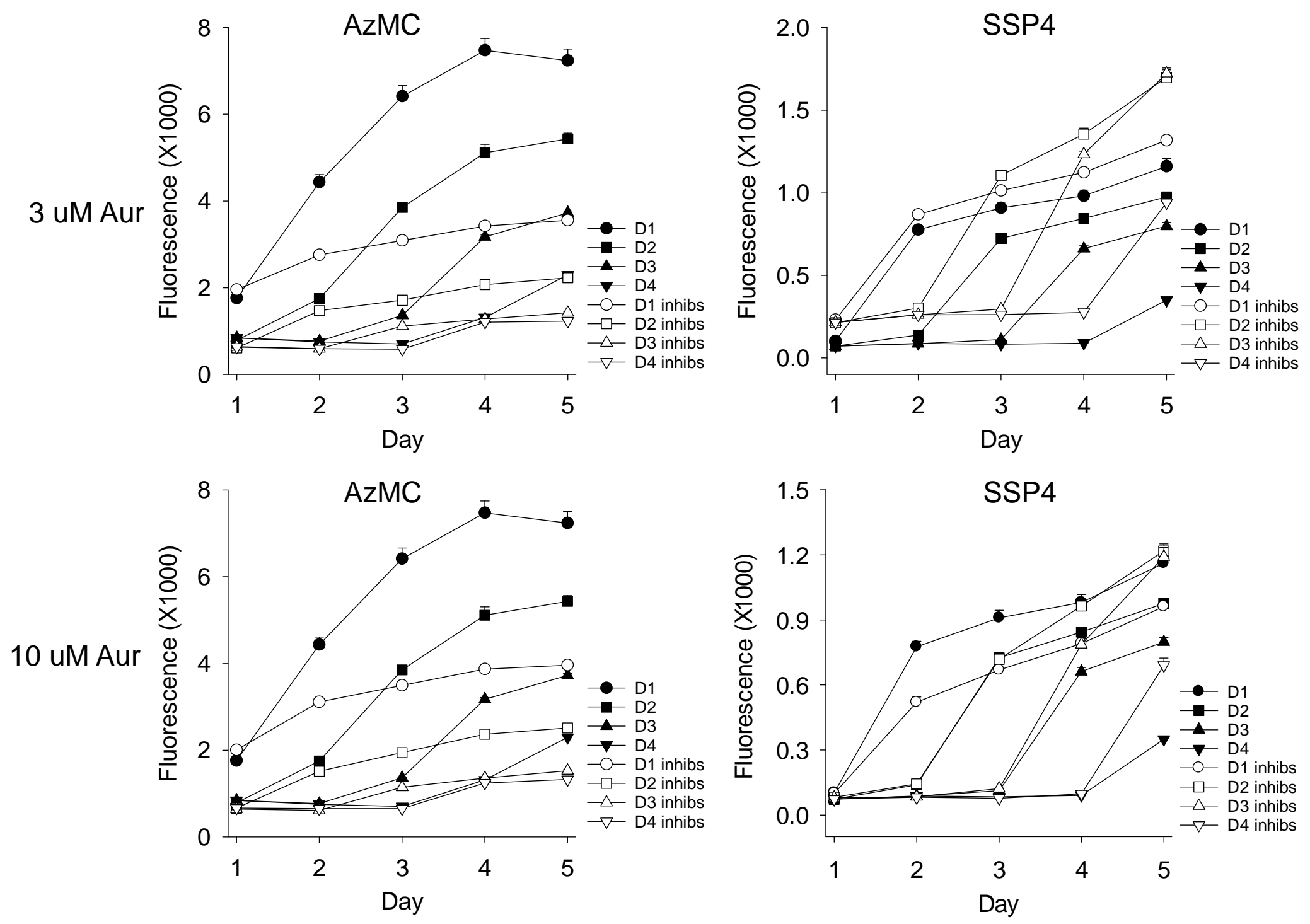
Fig. 5
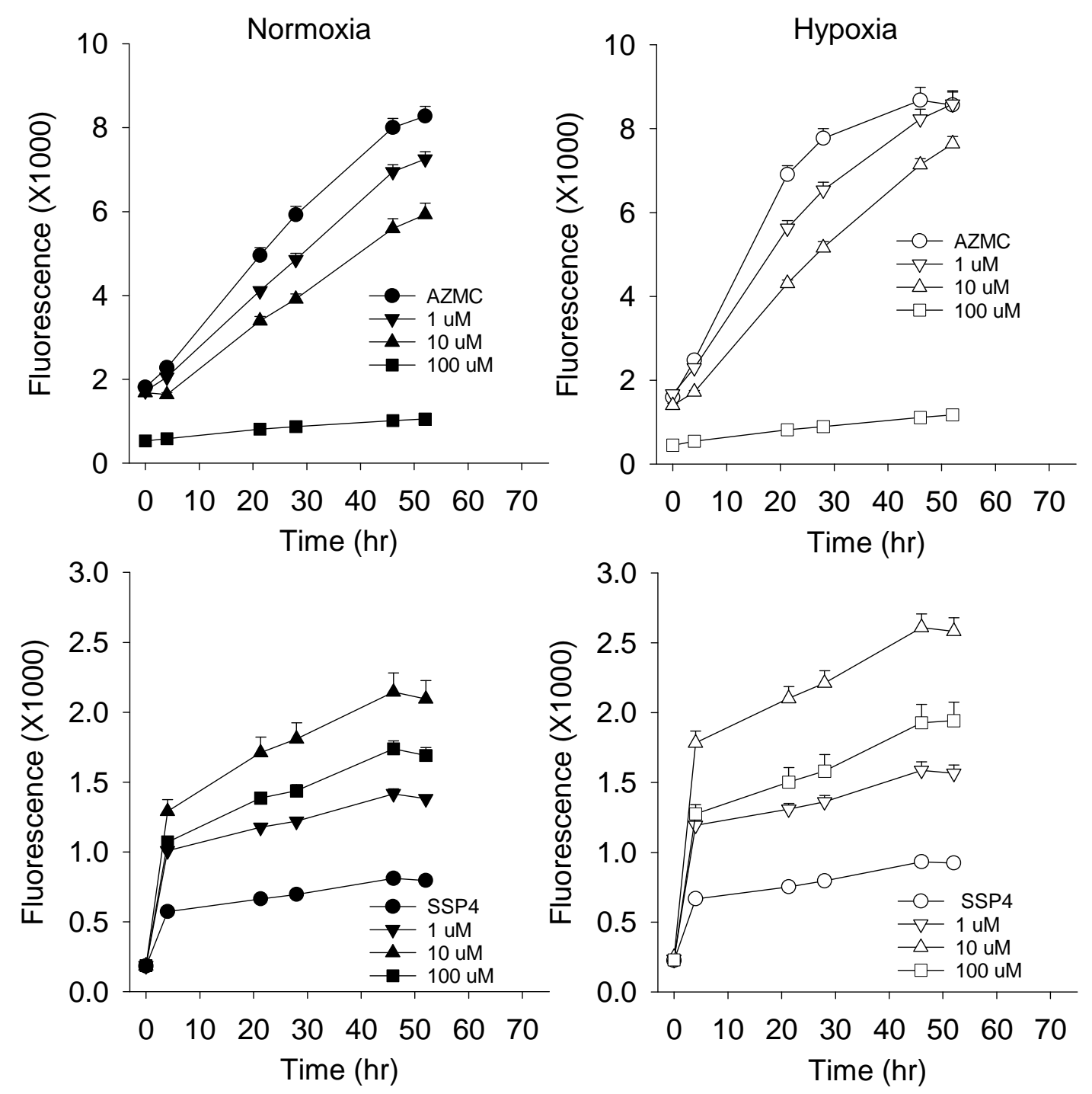
Fig. 6
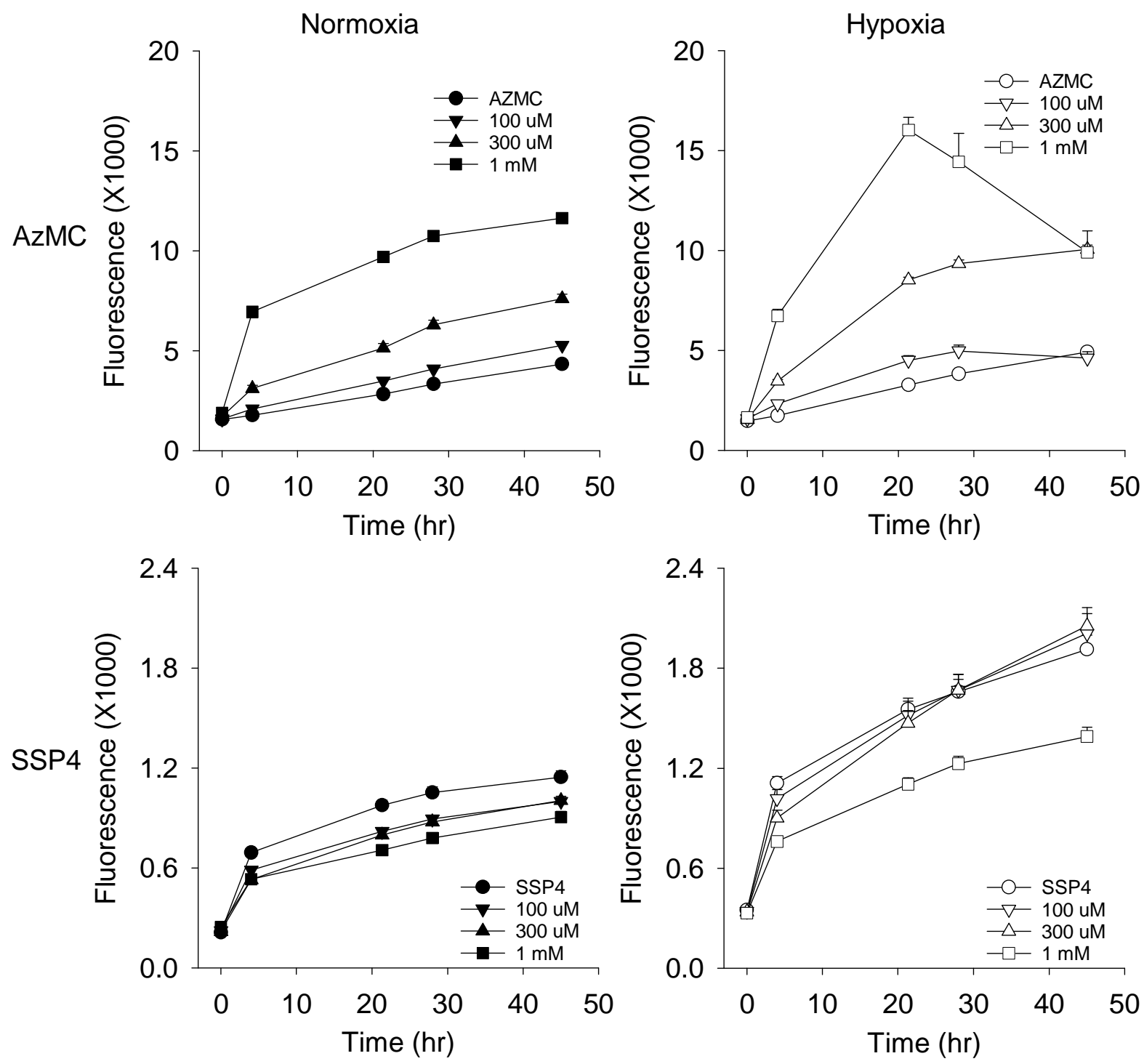
Fig. 7
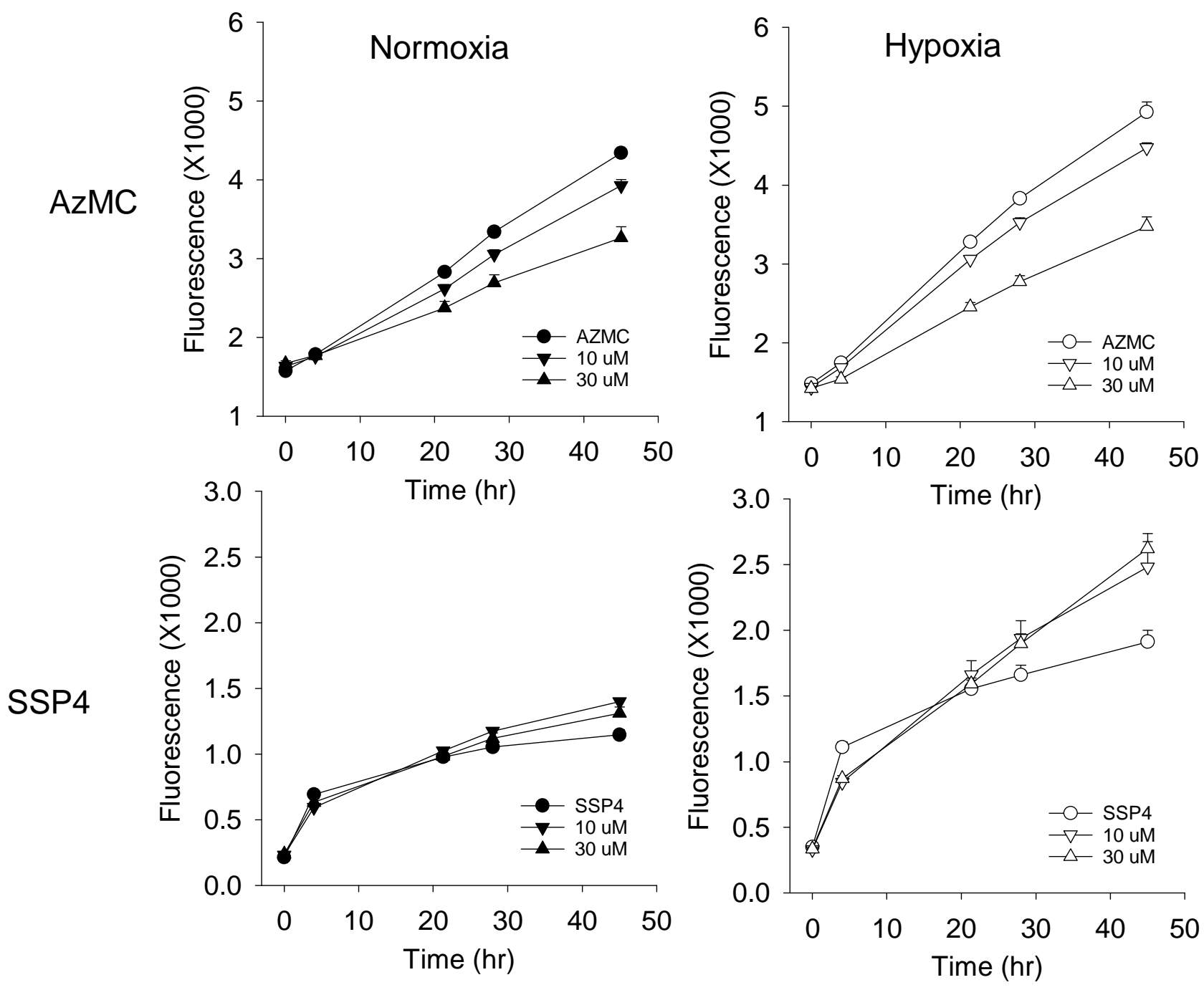
Fig. 8
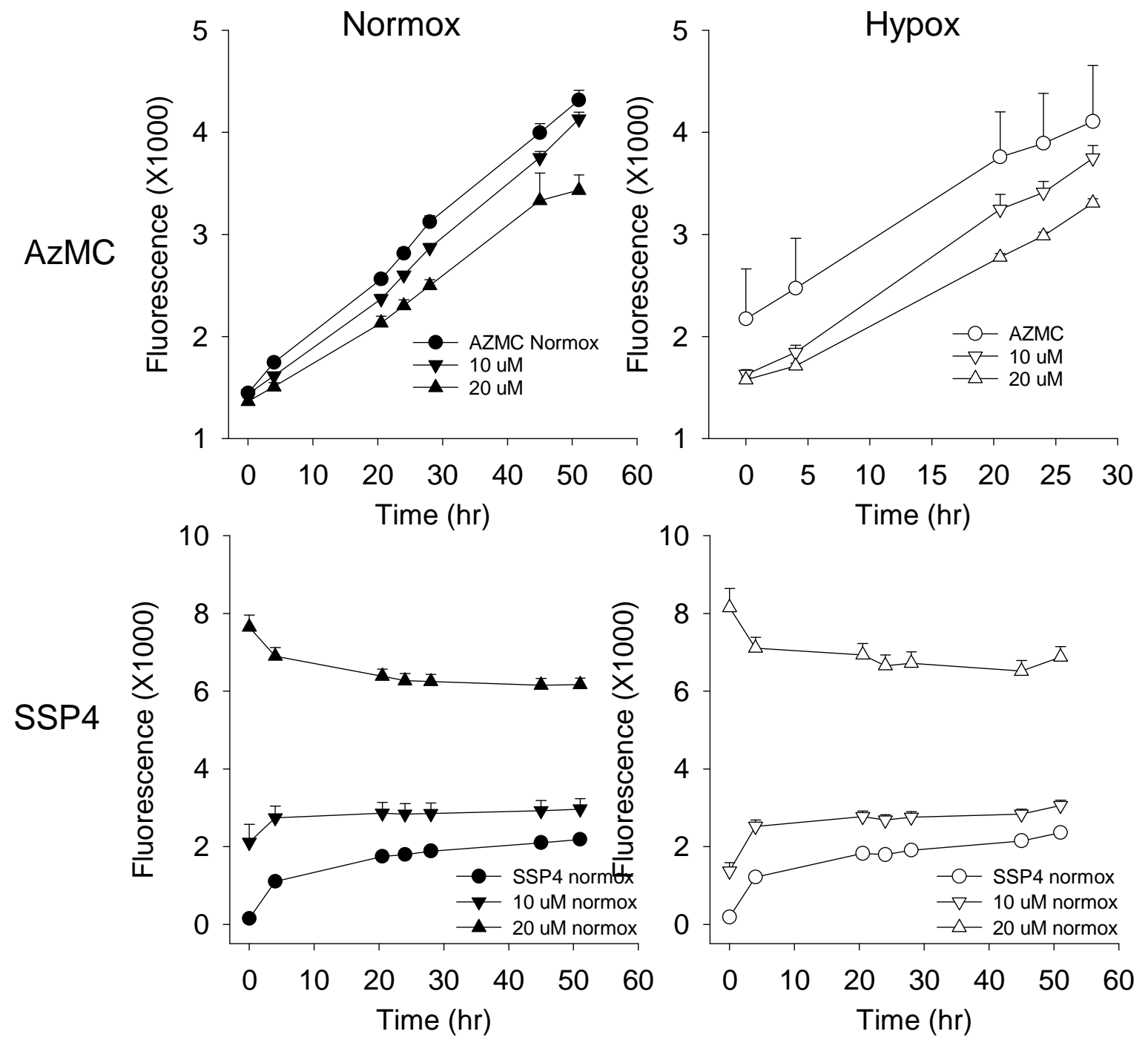
Fig. 9
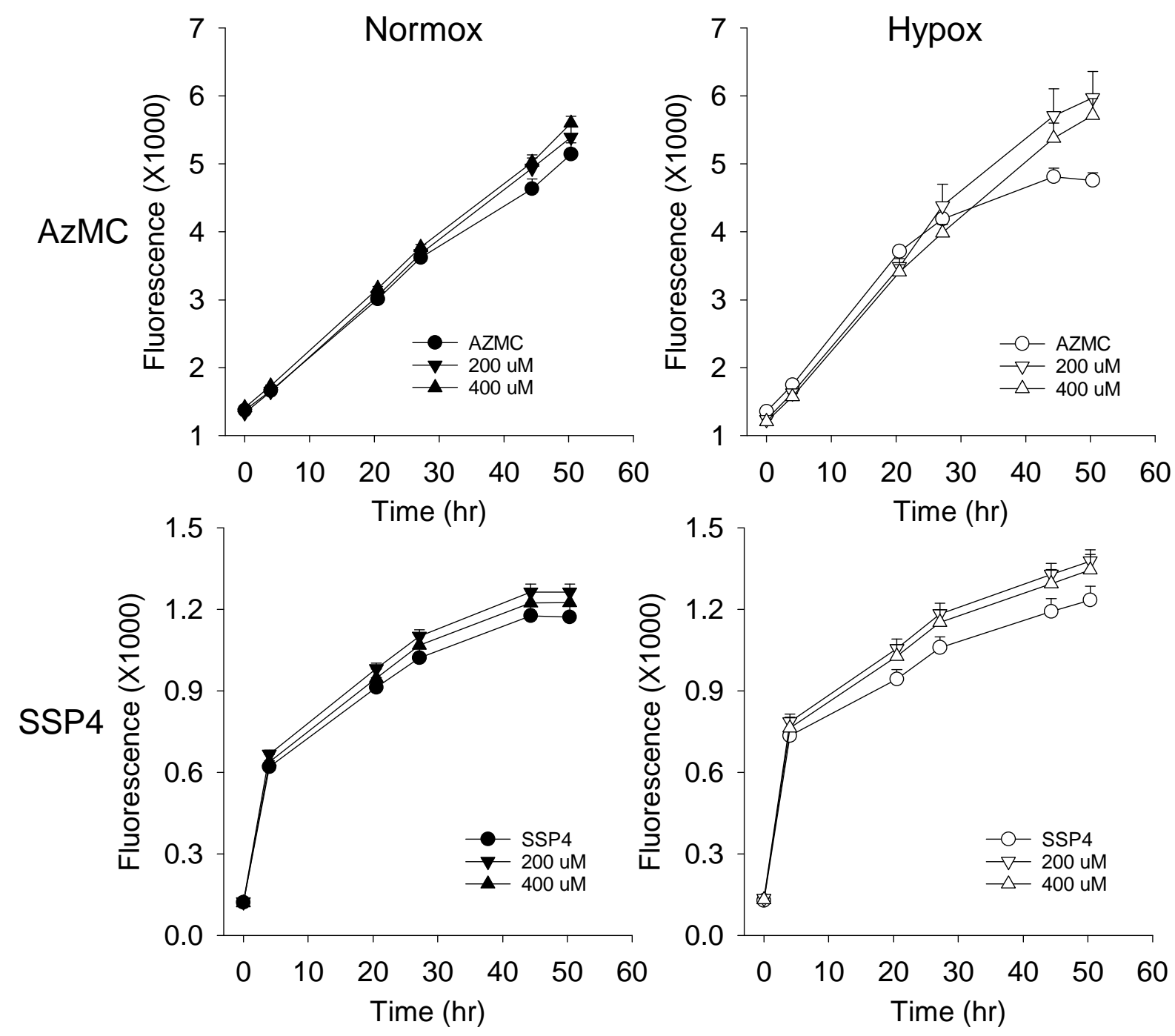
Fig. 10
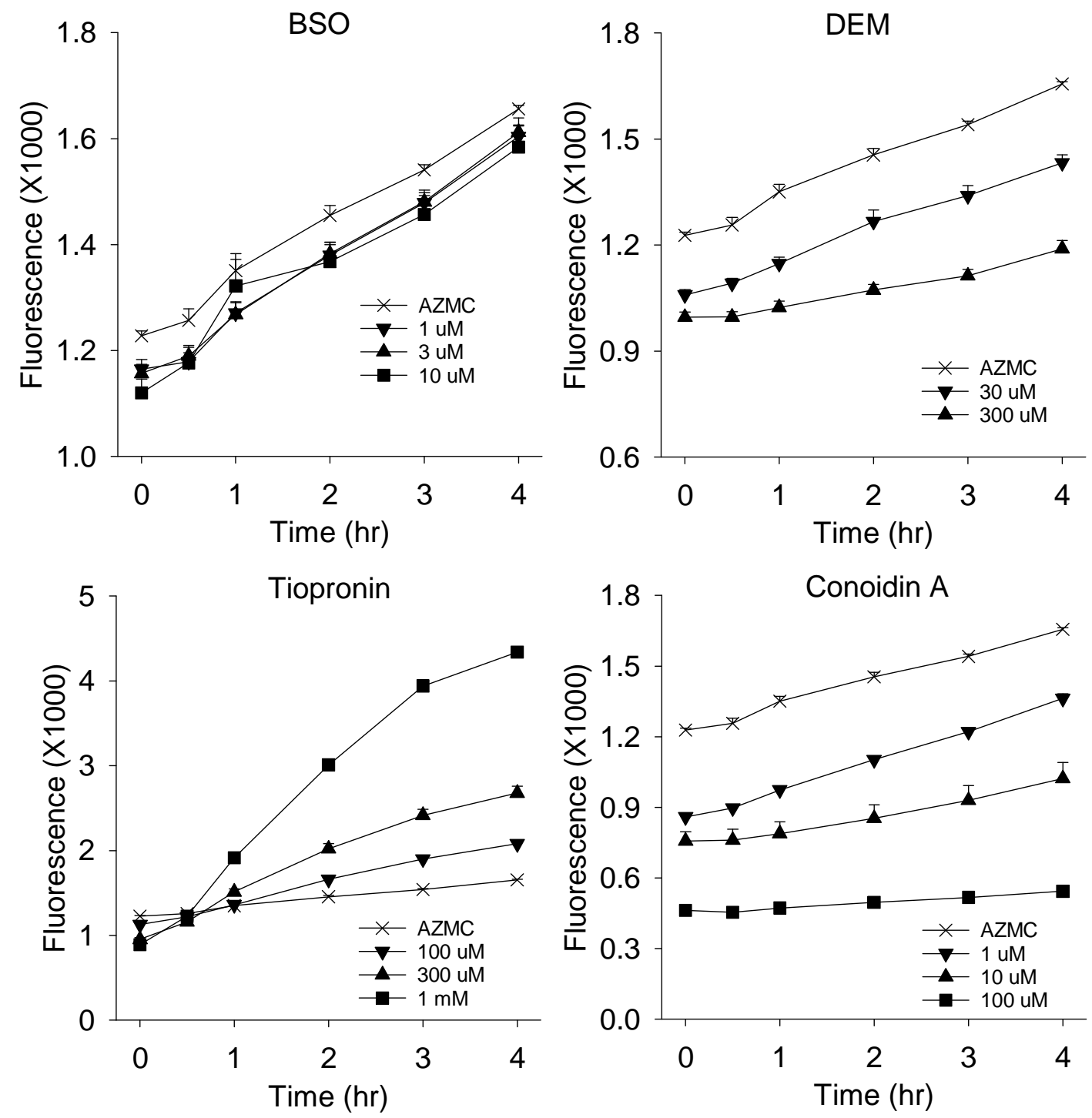
Fig. 11
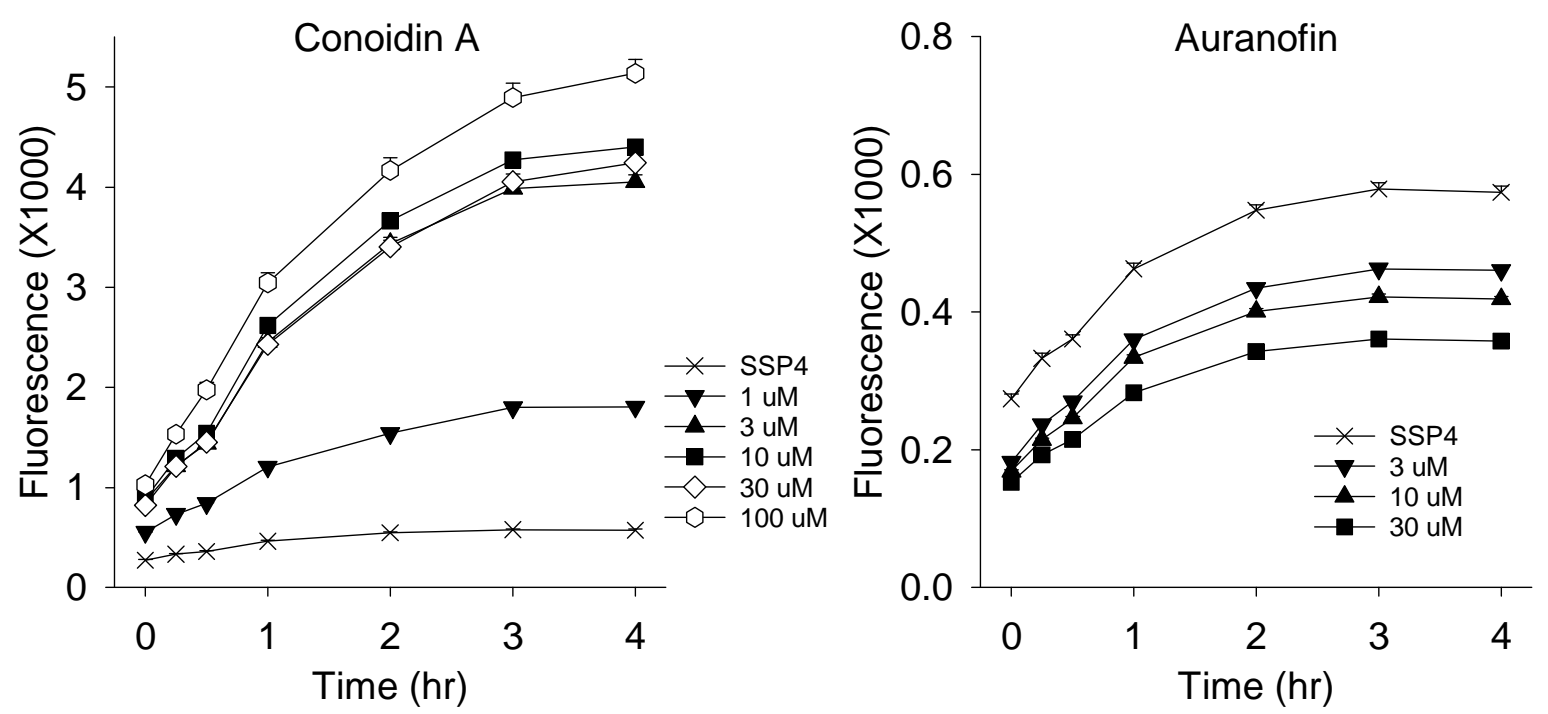
Fig. 12

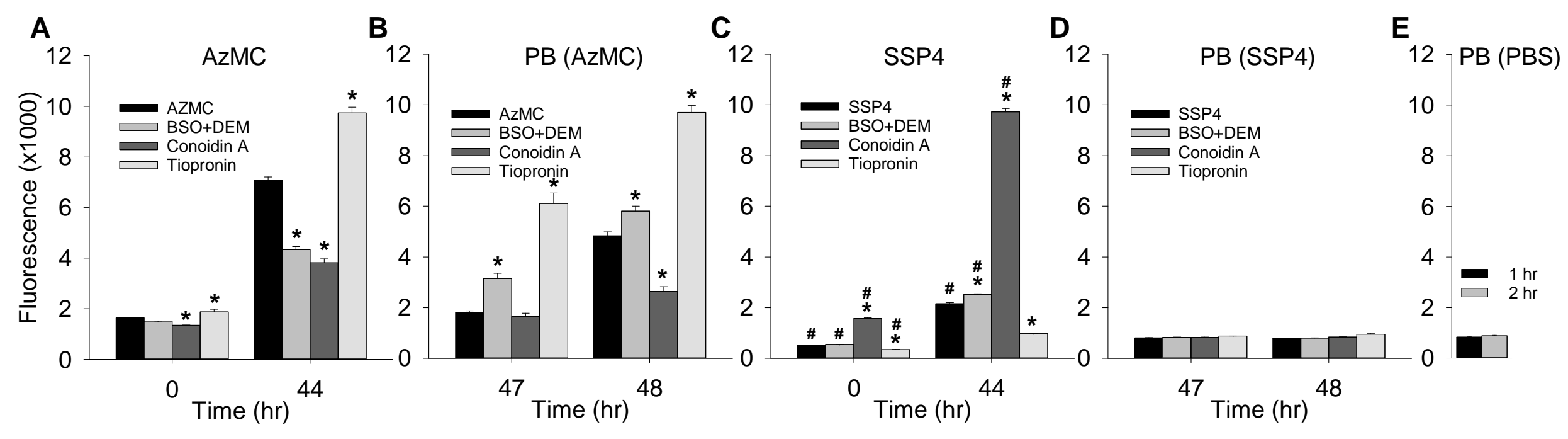


Reactive oxygen species (ROS) and reactive sulfide species (RSS) are chemically and biologically similar.

Evolution of antioxidant pathways is more consistent with RSS metabolism than with ROS metabolism

Here we show that canonical inhibitors of ROS antioxidant pathways affect RSS in HEK293 cells independent of ROS.

These results indicate that antioxidant pathways are involved in RSS metabolism in cells.

RSS may be the actual effector pathway(s) of ROS antioxidant therapies. 